OPEN ACCESS

Edited by:

Patrizia Ballerini,

University of Studies G. d'Annunzio

Chieti and Pescara, Italy

Reviewed by:

Andreas Von Knethen,

Goethe University Frankfurt, Germany

Chi Chien Lin,

National Chung Hsing University,

Taiwan

*Correspondence:

Zhiying Hao

drzhiyingh@163.com

Specialty section:

This article was submitted to Inflammation Pharmacology,

a section of the journal

Frontiers in Pharmacology

Received: 14 May 2021 Accepted: 03 August 2021 Published: 19 August 2021

Citation:

Li Y, Zhang L, Zhang P and Hao Z (2021) Dehydrocorydaline Protects Against Sepsis-Induced Myocardial Injury Through Modulating the TRAF6/

$N F-\kappa B$ Pathway.

Front. Pharmacol. 12:709604. doi: 10.3389/fphar.2021.709604

\section{Dehydrocorydaline Protects Against Sepsis-Induced Myocardial Injury Through Modulating the TRAF6/NF-kB Pathway}

\author{
Yadong $\mathrm{Li}^{1}$, Li Zhang ${ }^{2}$, Ping Zhang ${ }^{2}$ and Zhiying $\mathrm{Hao}^{3 *}$ \\ ${ }^{1}$ Department of Emergency, Second Hospital of Shanxi Medical University, Taiyuan, China, ${ }^{2}$ Department of Hemotology, Renmin \\ Hospital of Wuhan University, Wuhan, China, ${ }^{3}$ Department of Pharmacy, Shanxi Cancer Hospital, Taiyuan, China
}

We aim to investigate the effect and mechanism of dehydrocorydaline (Deh), an alkaloidal component isolated from Rhizoma corydalis, in the treatment of sepsis-mediated myocardial injury. Lipopolysaccharide (LPS) was taken to construct an in-vitro sepsismyocardial injury models H9C2 cardiomyocytes. The in-vivo model of sepsis in C57BL/6 mice was induced by intraperitoneal injection of Escherichia coli (E. coli). The in-vitro and invivo models were treated with Deh in different concentrations, respectively. Hematoxylineosin (HE) staining, Masson staining, and immunohistochemistry $(\mathrm{HCC})$ staining were taken to evaluate the histopathological changes of the heart. ELISA was applied to evaluate the levels of inflammatory factors, including IL-6, IL-1 $\beta, T N F \alpha$, IFN $\gamma$, and oxidized factors SOD, GSH-PX in the plasma or culture medium. Western blot was used to measure the expressions of Bax, Bcl2, Caspase3, iNOS, Nrf2, HO-1, TRAF6, NF-kB in heart tissues and cells. The viability of $\mathrm{H} 9 \mathrm{C} 2$ cardiomyocytes was detected by the CCK8 method and BrdU assay. The ROS level in the H9C2 cardiomyocytes were determined using immunofluorescence. As a result, Deh treatment improved the survival of sepsis mice, reduced TUNEL-labeled apoptosis of cardiomyocytes. In vitro, Deh enhanced the viability of LPS-induced H9C2 cardiomyocytes and inhibited cell apoptosis. Additionally, Deh showed significant anti-inflammatory and anti-oxidative stress functions via decreasing IL-1 $\beta, \mathrm{IL}-6, \mathrm{TNF} \alpha$, and IFN $\gamma$ levels, mitigating ROS level, up-regulating Nrf2/ HO-1, SOD, and GSH-PX expressions dose-dependently. Mechanistically, Deh inhibited TRAF6 expression and the phosphorylation of NF-kB p65. The intervention with a specific inhibitor of TRAF6 (C25-140) or NF-kB inhibitor (BAY 11-7082) markedly repressed the protective effects mediated by Deh. In conclusion, Deh restrains sepsis-induced cardiomyocyte injury by inhibiting the TRAF6/NF-kB pathway.

Keywords: sepsis, myocardial injury, dehydrocorydaline, TRAF6/NF-кB pathway, inflammation

\section{INTRODUCTION}

Sepsis is a clinical syndrome that mainly manifests as a systemic inflammatory response caused by infection, and has a high mortality rate in countries around the world (Innocenti et al., 2020). Septic myocardial injury, as one of the most prevailing clinical complications, is commonly observed in the late stage of severe sepsis, and the mortality rate of patients with sepsis combined with cardiac 
dysfunction is $\mathbf{7 0 - 9 0 \% ~ ( H o c h s t a d t ~ e t ~ a l . , ~ 2 0 1 1 ) . ~ T h e ~ c r u c i a l ~}$ factors of myocardial damage are changes in hemodynamics, inflammation, mitochondrial damage and oxidative stress induced by sepsis (Lewis et al., 2012). On the other hand, unbalanced oxidative stress following sepsis also contributes to the damage of mitochondrion functions, which leads to the insufficient production of mitochondrial ATP, resulting in fatal energy failure of the cardiomyocytes, and ultimately leads to myocardial injury (Rocha et al., 2012). Therefore, studying the mechanism of sepsis-induced inflammation and oxidative stress helps the treatment of sepsis-induced myocardial injury.

TLR4, one member of toll-like receptors (TLRs), has been found to exert a prominent effect on sepsis occurrence and maintenance (Oyama et al., 2004; Hennessy et al., 2010). Lipopolysaccharide (LPS) is a major component of the gram-negative bacilli cell wall. As a pathogen-related molecular pattern, it can be specifically recognized by TLR4 to initiate intracellular signal transduction, thereby mediating immune and inflammatory responses (Zeuke et al., 2002; Ha et al., 2008). Previous studies on myocardial injury have demonstrated that a number of drugs alleviate LPS-mediated myocardial injury by regulating TLR4. For example, Clemastine Fumarate contributes to the prevention of myocardial ischemiareperfusion injury by regulating the TLR4/PI3K/Akt signaling pathway (Yuan et al., 2020). Furthermore, ginsenoside Rg1 alleviates myocardial cell apoptosis and inflammation by inhibiting the TLR4/NF- $\mathrm{kB} / \mathrm{NLR}$ family pyrin domain containing three signaling pathway (Luo et al., 2020).

TNF receptor-associated factor 6 (TRAF6) was one of the first identified downstream signal proteins of TLRs. Located at the central point of the convergence of signals induced by TLR and TNF receptor families, TRAF6 is widely involved in the inflammatory response and immune response mainly by mediating inflammation and apoptotic signaling pathways (Inoue et al., 2007). TRAF6 has an important effect on the activation of the intracellular signal transduction pathway mediated by TLR4. For instance, the limitation of bromodomain and extraterminal domain protein expression inhibits the TLR4/TRAF6/NF- $\kappa B$ signaling pathway, thus restraining acute myocardial infarction (Sun et al., 2015). Therefore, examining the function and mechanism of TLR4/ TRAF6 in LPS-induced myocardial injury is expected to reveal a novel therapeutic approach for sepsis-induced myocardial injury.

2,3,9,10-tetramethoxy-13-methyl-5,6-dihydroisoquinolino [2,1-b] isoquinolin-7-ium (Deh; molecular formula, $\mathrm{C}_{22} \mathrm{H}_{24} \mathrm{NO}_{4}$ ) is a quaternary ammonium salt alkaloid extracted from fumarine (Huo et al., 2018). Deh has been reported to have beneficial effects in the treatment of depression and melanoma. For instance, Deh can alter the content of monoamine in brains by limiting uptake2 monoamine transporters, thus exerting its antidepressant effects (Jin et al., 2019). Additionally, it restrains cell proliferation, migration and invasion by inhibiting the MEK1/ 2-ERK1/2 signaling pathway in melanoma (Hu et al., 2019). Furthermore, Deh limits the increase of mitochondrial membrane potential and ATP depletion in macrophages induced by LPS and inhibits the release of IL-1 $\beta$ and IL-6 through macrophages (Ishiguro et al., 2011). Therefore, exploring the effects of Deh on sepsis-mediated myocardial injury may be of interest.

The present study revealed that Deh enhanced the viability of cardiomyocytes in an Escherichia coli (E. coli)- or LPS-induced sepsis model, inhibited cell apoptosis, reduced IL-1 $\beta$ and TNFa levels, and upregulated the expressions of superoxide dismutase (SOD) and glutathione peroxidase (GSH-PX) in the plasma and culture medium. Additional experiments demonstrated that Deh alleviated LPS-induced myocardial injury via the inhibiting TRAF6/NF- $\kappa \mathrm{B}$ signaling pathway and activating Nrf2/HO-1 pathway. Collectively, the present study revealed the protective mechanism of Deh in myocardial injury, providing a reference for sepsis-mediated myocardial injury treatment.

\section{MATERIALS AND METHODS}

\section{Sepsis Animal Model and Drug Treatment}

A total of 80 male C57B6/L mice (age, 8-10 weeks, 20-22 g) were obtained from and kept in the Animal Research Center of the Shanxi Medical University (animal license: SYXK (Jin)2021-0001). All mice were kept under controlled lighting (light: dark, 12:12 h) and temperature $\left(22 \pm 1^{\circ} \mathrm{C}\right)$ conditions with free access to food and water for 10 days to acclimate to the environment. The mice were randomly divided into six groups, including sham group $(n=10$ per group), Deh group (20 mg/kg, $n=10)$, Sepsis group ( $n=15)$, Sepsis + Deh (5 mg/kg group, $n=15)$, Sepsis + Deh (10 mg/kg group, $n=$ 15), Sepsis + Deh (20 mg/kg group, $n=15)$. Deh was administered via intraperitoneal injection (once every $24 \mathrm{~h}$ ). An in vivo sepsisinduced myocardial injury model was constructed as previously described (Song et al., 2018). Briefly, a total number of $3.5 \times 10^{6}$ Escherichia coli (ATCC25922) was injected intraperitoneally into the mice. After $30 \mathrm{~min}$, the mice in the Sepsis group were treated with Deh $(5,10$ and $20 \mathrm{mg} / \mathrm{kg}$ body weight) via intraperitoneal injection for three consecutive days. Deh (cat. no. N2090; purity $>98 \%$ ) was obtained from APeXBIO Technology LLC and the treatment dose was selected based on a previous study (Bin et al., 2019). The survival rate of mice in each group was monitored hourly. $6 \mathrm{~h}$ or $24 \mathrm{~h}$ after the Escherichia coli injection, the peritoneal lavage fluid and serum were collected for further analysis.

\section{Liver and Kidney Function Test}

Following centrifugation $\left(500 \mathrm{~g}\right.$ for $10 \mathrm{~min}$ at $4^{\circ} \mathrm{C}$ ), the supernatant of peritoneal lavage fluid and serum was collected, stored at $-80^{\circ} \mathrm{C}$ and used to examine the levels of plasmatic inflammatory factors (IFN $\gamma, \mathrm{IL}-6$, IL- $1 \beta$ and TNFa) and antioxidant factors (SOD and GSH-PX) using their detection kits. For the evaluation of liver and kidney function, the levels of creatinine, urea nitrogen, aspartate aminotransferase (AST), and alanine aminotransferase (ALT) in the supernatant of peritoneal lavage fluid and serum were measured using an automatic biochemical analyzer (AU800; Olympus Corporation, Tokyo, Japan).

\section{Bacterial Counts}

The collected peritoneal lavage fluid and serum were subjected to serial $\log$ fold dilution in sterile saline. 10-fold serial 
dilutions of the bacterial load in blood and peritoneal lavage fluid were plated on tryptic soy blood agar plates, which were incubated for $24 \mathrm{~h}$ at $37 \mathrm{C}$. After the incubation, the bacterial colonies were counted and expressed as $\log \mathrm{CFU} / \mathrm{ml}$ blood or peritoneal fluid.

\section{Heart Tissue Collection}

All mice received deep anesthesia by intravenous injection of $100 \mathrm{mg} / \mathrm{kg}$ phenobarbital sodium (CAS:57-30-7, Sigma-Aldrich). The hearts of the mice were removed, and one half of the hearts was used for histopathological evaluation and the other half was used for western blotting. All procedures were conducted following the Guidelines for the Care and Use of Laboratory Animals issued by the National Institutes of Health (NIH publication, 2011 revision). All animal studies have been approved by the Ethics Committee of the Shanxi Cancer Hospital (Taiyuan, China, Approval number: SXZL-2021-LL-008).

\section{Cardiomyocyte Culture and Treatment}

H9C2 cells (Cat.No. CRL-1446, American Type Culture Collectionm, USA), derived from rat embryonic ventricular myocytes, were cultured in high glucose $(4,500 \mathrm{mg} / \mathrm{l}) \mathrm{DMEM}$ (Gibco; Thermo Fisher Scientific, Inc.) supplemented with 10\% FBS (Gibco; Thermo Fisher Scientific, Inc.), $100 \mathrm{U} / \mathrm{ml}$ penicillin (Beijing Solarbio Science and Technology Co., Ltd.) and $100 \mathrm{mg} / \mathrm{ml}$ streptomycin (Wuhan Fortuna Chemical Co., Ltd.). Cells were maintained in a standard culture dish (Becton, Dickinson and Company) at $37^{\circ} \mathrm{C}$ with $5 \% \mathrm{CO}_{2}$ in a wet environment on a monolith, and the medium was replaced every 2 days.

\section{Cell Grouping and Treatment}

H9C2 cells were divided into the following groups: 1) Control; 2) Deh $(20 \mu \mathrm{g} / \mathrm{ml})$; 3) LPS; 4) LPS + Deh $(5 \mu \mathrm{g} /$ $\mathrm{ml}) ; 5) \mathrm{LPS}+\operatorname{Deh}(10 \mu \mathrm{g} / \mathrm{ml}) ; 6) \mathrm{LPS}+\operatorname{Deh}(20 \mu \mathrm{g} / \mathrm{ml}) ; 7) \mathrm{LPS}$ + C25-140; 8) LPS + C25-140 + Deh $(10 \mu \mathrm{g} / \mathrm{ml}) ; 9) \mathrm{LPS}+\mathrm{BAY}$ 11-7082; 10) LPS + BAY 11-7082 + Deh $(10 \mu \mathrm{g} / \mathrm{ml})$. Inflammatory damage was induced by $10 \mu \mathrm{g} / \mathrm{ml}$ LPS treatment. The cells were dealt with E. coli LPS $(10 \mu \mathrm{g} / \mathrm{ml}$; serotype 0111: B4; Sigma-Aldrich; Merck KGaA) to induce an in-vitro sepsis model. The TRAF6 inhibitor C25-140 (Cat. No.HY-120934, MedChemExpress), and the NF- $\mathrm{BB}$ inhibitor BAY 11-7082 (Cat. No. HY-13453, MedChemExpress), were used for pretreatment of the cells at a concentration of 5 and $1 \mu \mathrm{M}$ for $2 \mathrm{~h}$, respectively.

\section{Cell Counting Kit 8 Assay}

The viability of $\mathrm{H} 9 \mathrm{C} 2$ cells was examined using a CCK8 (Beyotime Institute of Biotechnology) assay according to the manufacturer's protocols. Briefly, H9C2 cells were inoculated into 96-well plates $\left(1 \times 10^{5}\right.$ cells $\left./ \mathrm{ml}\right)$ and incubated for $24 \mathrm{~h}$ in a $37^{\circ} \mathrm{C}$ incubator with $95 \% \mathrm{O}_{2}$ and $5 \% \mathrm{CO}_{2}$. After the treatments were finished, $10 \mu \mathrm{l}$ CCK8 reagent was added to each well. Subsequently, the cells underwent a 3 -h incubation at $37^{\circ} \mathrm{C}$. Ultimately, the absorbance value was determined at $450 \mathrm{~nm}$. Each experiment was repeated three times and each measurement was made three times.

\section{ELISA}

After the treatment was finished, the culture medium of H9C2 cells was collected and the cells in the medium were removed by centrifugation at room temperature. The levels of the inflammatory factors (IFN $\gamma$,IL-6, IL- $1 \beta$ and TNFa) and oxidative stress factors (SOD and GSH-PX) in the mouse plasma supernatant or cell culture medium were determined, and the experiments were performed strictly according to the requirements of the kit. The aforementioned detection kits, including IFN $\gamma$ (Cat.No. 70-EK280/3-96), IL-6 (Cat.No. 70EK206/3-96), IL-1 (Cat.No. 70-EK201B/3-96) and TNFa (Cat.No. 70-EK282/3-96) were purchased from MultiSciences (Hangzhou, China). The detection kits of SOD (Cat. No. A001-3-2) and GSH-PX (Cat. No. A005-1-2) were purchased from Nanjing Jiancheng Bioengineering Institute (Nanjing, China).

\section{Western Blotting}

Following treatment of mouse myocardial tissues or H9C2 cells, the heart tissues and cells were collected. Subsequently, RIPA lysis buffer (Roche Diagnostics) was used for isolation of total protein. The total nucleoprotein was extracted using a Nucleoprotein Extraction Kit [Order NO. C500009, Sangon Biotech (Shanghai) Co., Ltd.]. Total protein $(50 \mu \mathrm{g})$ was subjected to SDS-PAGE at $100 \mathrm{~V}$ for $\sim 2 \mathrm{~h}$. Next, the separated proteins were electrically transferred to the PVDF membranes. Then, the membranes were blocked with $5 \%$ skimmed milk powder for $1 \mathrm{~h}$ at room temperature, rinsed with TBS with $0.1 \%$ Tween-20 (TBST) three times for $10 \mathrm{~min}$ each, and incubated overnight at $4^{\circ} \mathrm{C}$ with TRAF6 (dilution, 1: 1,000; cat. no. ab218575; Abcam), phosphorylated-(p-) NF- $\kappa B$ (phospho S536) (dilution, 1:1,000; cat. no. ab86299; Abcam), NF- $\kappa \mathrm{B}$ (dilution, 1:1,000; cat. no. ab32536; Abcam), iNOS (dilution, 1:1,000; cat. no. ab178945; Abcam), Nrf2 (dilution, 1:1,000; cat. no. ab62352; Abcam), Heme Oxygenase 1 (dilution, 1:1,000; cat. no. ab68477; Abcam), Histone H3 (dilution, 1: 1,000; cat. no. ab1791; Abcam), Bax (dilution, 1:1,000; cat. no. ab32503; Abcam), Bcl2 (dilution, 1:1,000; cat. no. ab182858; Abcam), and Caspase3 (dilution, 1:1,000; cat. no. ab13847; Abcam) primary antibodies. After washing with TBST, the membranes were incubated with HRP-labeled anti-rabbit or anti-mouse secondary antibodies (dilution, 1:300, cat. no. ab205718; Abcam) for $1 \mathrm{~h}$ at room temperature. Subsequently, TBST was used to wash the membranes three times for 10 min each. Finally, western blot reagent (Invitrogen; Thermo Fisher Scientific, Inc.) was added for color imaging. ImageJ (Version: $1.52 \mathrm{v}$, National Institutes of Health) was used to analyze the gray values of each protein.

\section{5-Bromo-2-Deoxyuridine Assay}

A single cell suspension was prepared from H9C2 cells in each group during the logarithmic growth period and cells were inoculated into 24 -well plates at a density of $1 \times 10^{5}$ cells/well until the cells grew adherent to the wall. BrdU labeling reagent (Sigma-Aldrich; Merck $\mathrm{KGaA}$ ) was added according to the manufacturer's protocols, and the plates were placed in an incubator with $5 \% \mathrm{CO}_{2}$ at $37^{\circ} \mathrm{C}$. Following continuous cell 
culture for $48 \mathrm{~h}$, the cells underwent immunofluorescence staining according to the manufacturer's protocols of the BrdU Cell Proliferation Assay kit (Sigma, Shanghai, China). The nucleus was stained by DAPI (Beyotime, Shanghai, China). The positive cell quantity and the total number of DAPI-positive cells in three randomly selected fields were calculated and observed under a microscope. Cell proliferation rate $=$ number of BrdU-positive cells/number of DAPI-positive cells. The average cell proliferation rate of three visual fields was taken as the cell proliferation rate.

\section{H\&E Staining}

Myocardial tissues of mice were washed with normal saline and fixed with $4 \%$ paraformaldehyde for 30-50 min. Subsequently, the samples were washed, dehydrated, cleaned, soaked in wax, embedded and sliced. The sections were heated in an incubator at $45^{\circ} \mathrm{C}$, dewaxed, rinsed with alcohol of high to low concentration and distilled water for $5 \mathrm{~min}$, stained with hematoxylin for $5 \mathrm{~min}$, rinsed $3 \mathrm{~s}$ with tap water, rinsed with $1 \%$ hydrochloric acid ethanol for $3 \mathrm{~s}$, and stained with $5 \%$ eosin for $3 \mathrm{~min}$. Following dehydration, the sections were cleaned, installed and observed under a microscope.

\section{Immunohistochemical Staining}

Sections (5- $\mu \mathrm{m}$ thick) of the paraffin-embedded heart tissues were dewaxed in water, heated in $\mathrm{pH} 6.0$ antigen repair solution three times for $5 \mathrm{~min}$ each and washed with PBS. Subsequently, 3\% hydrogen peroxide solution was added. Sections were incubated in the dark for $20 \mathrm{~min}$ at room temperature, blocked with 5\% BSA (Beyotime, Shanghai, China) for $30 \mathrm{~min}$ at room temperature, washed and incubated overnight at $4^{\circ} \mathrm{C}$ with TRAF6 (dilution, 1: 500; cat. no. ab40675; Abcam) antibody. Then, the sections were washed two times with PBS and incubated for $50 \mathrm{~min}$ at room temperature. Following three washes with PBS, the sections were incubated for $4 \mathrm{~min}$ with $3,3^{\prime}$ diaminobenzidine tetrahydrochloride, and the positive color was tan brown. Next, the sections were rinsed with running water until the color faded. The sections were counterstained with hematoxylin for $\sim 3 \mathrm{~min}$, washed with tap water, underwent $1 \%$ hydrochloric acid ethanol differentiation for several seconds, and were washed with tap water until the ammonia turned blue. Subsequently, the sections were rinsed with tap water again. Following dehydration and blocking, the membranes were placed under a microscope for examination, image acquisition and analysis, and the integrated optical density was calculated using Image-Pro Plus (Version: 6.0, National Institutes of Health) software. For the detection of apoptotic cells in the heart, the TUNEL Assay Kit-HRP-DAB (cat. no. ab66110; Abcam) was used and the experimental processes were performed according to the instructions of the manufacturer. The nucleus was stained by DAPI (Beyotime, Shanghai, China). The number of TUNEL positive cells (every $0.1 \mathrm{~mm}^{2}$ ) was counted using Image-Pro Plus (Version: 6.0, National Institutes of Health) software.

\section{Masson Staining}

The hearts of mice were isolated, fixed with $4 \%$ paraformaldehyde, embedded by paraffin and sectioned. the
Masson's trichrome staining was performed using Masson's Trichrome Stain Kit (Cat.No.G1340, Solarbio, Beijing, China) according to the instructions of the producer. The sections were treated sequentially with hematoxylin and ferric oxide, acid fuchsin, phosphomolybdic acid, and acetic acid, and then neutral gum was used for the mounting of the sections.

\section{RT-PCR}

RT-PCR was used to detect TRAF6 mRNA level both in the heart and $\mathrm{H} 9 \mathrm{C} 2$ cells. TRIzol reagent (Invitrogen, USA) was used to isolate total RNA from the tissues or cells according to the manufacturer's instructions. Next, the RNA was reversetranscribed into cDNA using the Superscript First Strand Synthesis System (Invitrogen, USA). Then the qPCR amplification was analyzed using real-time quantitative PCR (SYBR Green) with an ABI-7900 Sequence Detection System (Applied Biosystems, USA). The relative expression of TRAF6 mRNA was quantified by the $2^{-\Delta \Delta \mathrm{Ct}}$ method using GAPDH as the internal control. The primers used in this study include: TRAF1, forward primers, $5^{\prime}$-CGAGGTTGGCATGACTTGAG-3', reverse primers, 5'-GCTCAATGTCCATGCCTCAG-3'; TRAF2, forward primers, $5^{\prime}$ - CTTCTCCCCAGCCTTCTTCA-3', reverse primers, $5^{\prime}$-AATGCGTCGATCACATGCTC- $3^{\prime}$; TRAF3, forward primers, $5^{\prime}$ - AGGTGTCCTCCCTGCTAGTA $-3^{\prime}$, reverse primers, $5^{\prime}$ - ACACTACAGGAAGCTGGGAC - $3^{\prime}$; TRAF4, forward primers, $5^{\prime}$ - CTGGAGGAGCTATCTGTGGG$3^{\prime}$, reverse primers, 5'- CGAGGAGATTGTCAAAGGCG-3'; TRAF5, forward primers, $5^{\prime}$ - TGAGGTCTTTGGTGGATGCT$3^{\prime}$, reverse primers, $5^{\prime}$ - CCAAATGAGCTTGCCACTGT-3'; TRAF6, forward primers, $5^{\prime}$-GGAAGAGCAGTCGTTTCCTG$3^{\prime}$, reverse primers, $5^{\prime}$-GTCACACCTCTACGGGGAAA- ${ }^{\prime}$; TRAF7, forward primers, $5^{\prime}$ - CCTGTCTGGTGTCTCTGTGT$3^{\prime}$, reverse primers, $5^{\prime}$ - ACAGTTTGCACCCCTGGATA-3'; GAPDH, 5'-ACCACAGTCCATGCCATCAC- $3^{\prime}$, reverse primers, $5^{\prime}$-TCCACCACCCTGTTGCTGTA-3'

\section{Reactive Oxygen Sepsis Detection}

For evaluating the oxidative stress level in $\mathrm{H} 9 \mathrm{C} 2$ cells, the DCFDA/H2DCFDA - Cellular ROS Assay Kit (ab113581, Abcam) was used. H9C2 cells were plated into a 6-well plate at a density of $3 \times 105 /$ well. The cells were incubated in a $5 \% \mathrm{CO} 2$ incubator at $37^{\circ} \mathrm{C}$. After the treatment on $\mathrm{H} 9 \mathrm{C} 2$ cells was finished, they were washed with PBS, stained with $2^{\prime}, 7^{\prime}$-dichlorofluorescin diacetate (DCFDA) solution $(20 \mu \mathrm{M})$ for $45 \mathrm{~min}$ at $37^{\circ} \mathrm{C}$. Next, the cells were washed with $1 \times$ Buffer for three times. The fluorescence signal was detected and observed using Olympus microscopy (BX53, Japan).

\section{Statistical Analysis}

SPSS software (version 20.0; IBM Corp.) was used for data analysis, and all data are presented as the mean \pm SD. Correlation was analyzed using a Pearson's correlation test. Student's $t$-test was performed for statistical analysis of twogroup data, while the difference between the two groups was analyzed using a $\chi^{2}$ test. The survival of mice was analyzed using the Kaplan Meier method. $p<0.05$ was considered to indicate a statistically significant difference. 


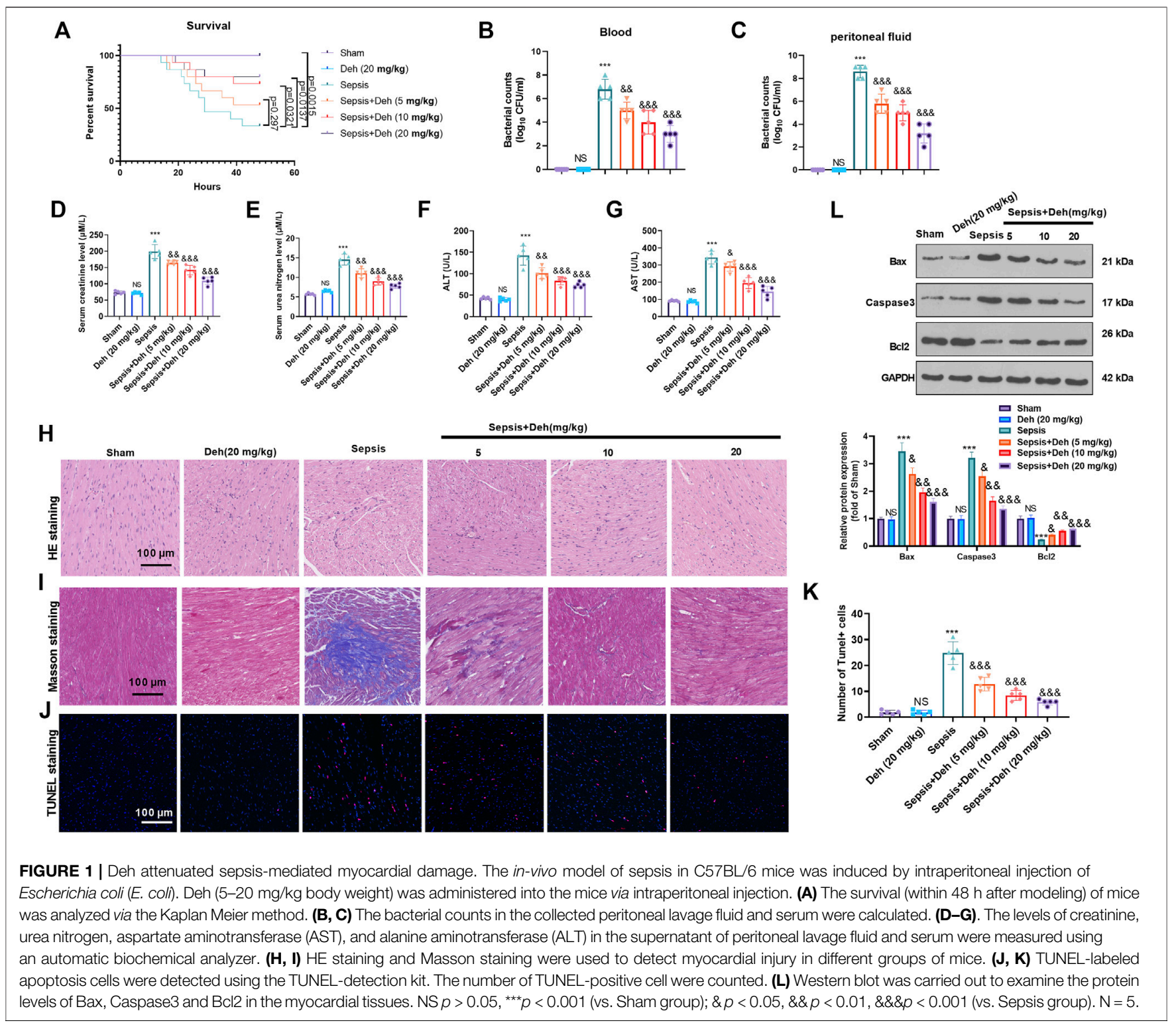

\section{RESULTS}

\section{Deh Attenuates Sepsis-Mediated Myocardial Injury}

To study the effect of Deh on sepsis-induced myocardial injury, E. coli-induced C57BL/6 mice were treated with Deh at different concentrations $(5,10$ and $20 \mathrm{mg} / \mathrm{kg})$ for 2 days. First, the survival of mice was analyzed. It was found that the survival rate was significantly reduced compared with the sham group $(p=0.0015)$. With the treatment of Deh, the survival rate increased, and the data had significance when Deh's dose was over $10 \mathrm{mg} / \mathrm{kg}$ (Figure 1A). The bacterial counts in the collected peritoneal lavage fluid and serum were significantly increased in the sepsis group ( $p<0.001$ vs. Sham group, Figures 1B,C). The treatment of Deh markedly reduced bacterial counts both in he collected peritoneal lavage fluid and serum $(p<0.01$ vs. Sepsis group,
Figures 1B,C). The liver and kidney functions were analyzed. The data showed that the mice in the sepsis group had signficantly increased level of creatinine, urea nitrogen, aspartate aminotransferase (AST), and alanine aminotransferase (ALT) in the serum ( $p<0.001$ vs. Sham group, Figures 1D-G). H\&E staining and Masson staining results revealed disordered myocardial cell structure, thickened muscle fibers, increased inflammatory cell infiltration and collagen fibers were detected in sepsis mice. Furthermore, Deh notably reduced LPS-induced myocardial injury in mice, and the higher the Deh concentration was, the higher the efficacy was for injury treatment (Figures $\mathbf{1 H}, \mathbf{I})$. The myocardial apoptosis was detected by TUNELstaining and western blot. The data showed that the TUNELpositive cells, Caspase 3 and Bax protein expressions in the heart tissues of sepsis mice increased, and Bcl2 was significantly downregulated ( $p<0.05$ vs. sham group, Figures 1J-L), whereas Deh treatment markedly decreased TUNEL-labeled 

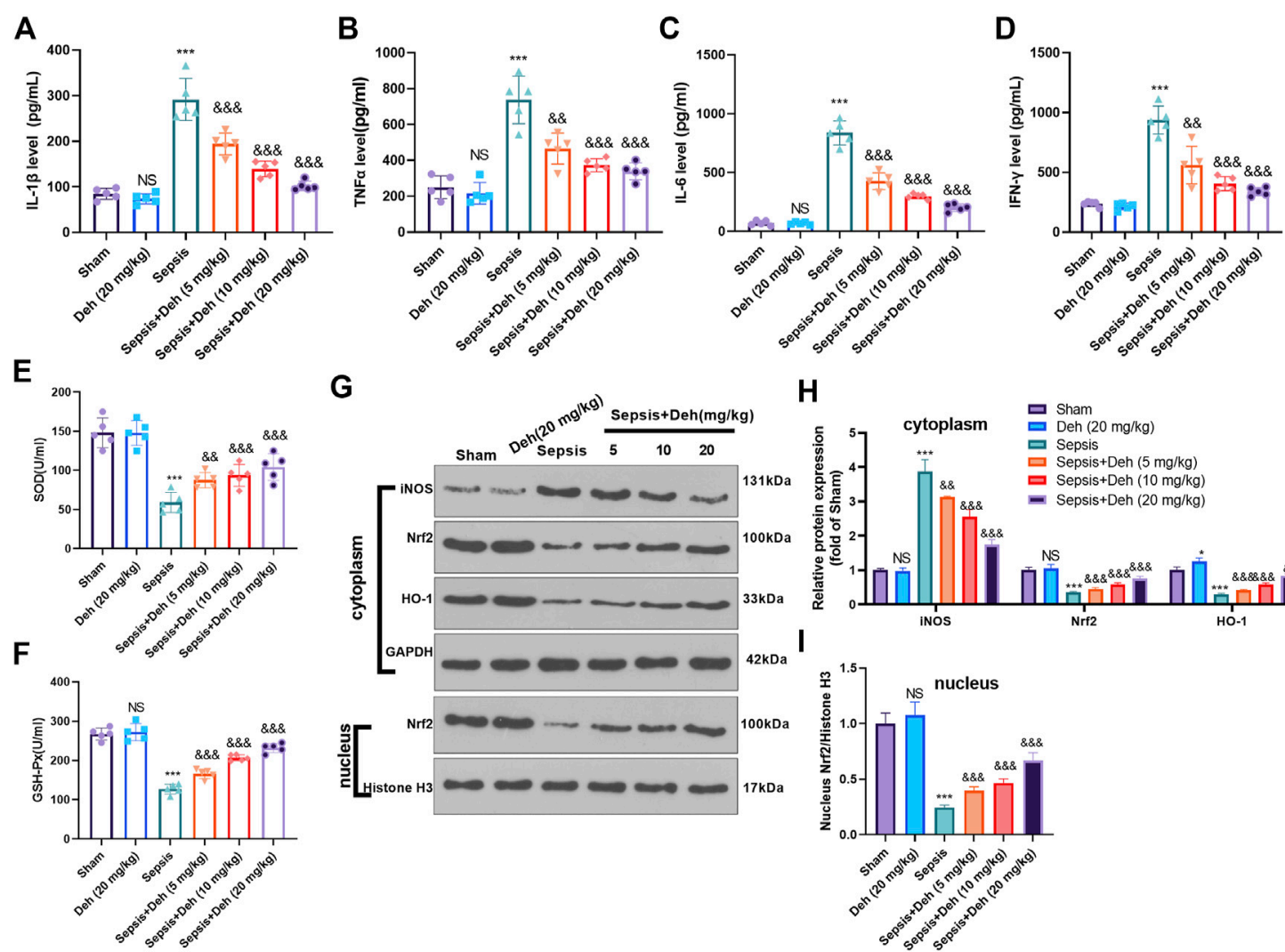

FIGURE 2 | Deh modulated sepsis-mediated inflammation and oxidative stress. (A-D) ELISA method was performed to detect IL-1 $\beta$ (A), TNF $\alpha$ (B), IL-6 (C), and IFN $\gamma$ (D) levels in the plasma of mice in each group. (E, F) The SOD and GSH-PX detection kits were applied to detect SOD (E) and GSH-PX (F) levels in the plasma of mice in each group. (G, I). The protein level of iNOS, Nrf2/HO-1 in the whole cell or nucleus of heart was detected by western blot. NS $p>0.05$, ${ }^{\star \star \star} p<0.001$ (vs. Sham group); \&\& $p<0.01, \& \& \& p<0.001$ (vs. Sepsis group). $\mathrm{N}=5$.

cardiomyocytes, inhibited Bax and Caspase 3 expression, and promoted Bcl2 level in a dose-dependent manner ( $p<0.05$ vs. sepsis group Figures 1J-L). Therefore, Deh exhibited protective effects on sepsis-induced myocardial injury in mice.

\section{Deh Attenuates Sepsis-Mediated Inflammation and Oxidative Stress}

The levels of inflammatory factors (IL-1 $\beta$, TNF $\alpha$, IL- 6 and IFN $\gamma$ ) and oxidizing factors (SOD and GSH-PX) in the serum were evaluated using the detection kits. The statistical analysis indicated that, compared with those in the sham group, IL-1 $\beta$, TNF $\alpha$, IL-6, and IFN $\gamma$ levels in the Sepsis group were upregulated, while SOD and GSH-PX levels were downregulated (Figures 2A-F). Additionally, Deh treatment reduced IL-1 $\beta, T N F a$, IL-6, and IFN $\gamma$ expressions in the plasma in a dose-dependent manner (Figures 2A-D) and increased the expression levels of SOD and GSH-PX (Figures 2E,F). The protein level of Nrf2/HO-1 and iNOS in the heart was detected by western blot. As the data showed, iNOS was significantly increased in the sepsis group, while Nrf2 and HO-1 in the whole cell, and Nrf2 in the nucleus were all repressed (compared with sham group, Figures 2G-I). Interestingly, the administration of Deh significantly repressed
iNOS, and promoted cytoplasmic Nrf2, HO-1 and nucleus Nrf2 levels (compared with sepsis group, Figures 2G-I). These results indicated that Deh alleviated the LPS-induced inflammatory response and promoted the expression of antioxidant stress factors.

\section{Deh Attenuates LPS-Mediated H9C2 Cell Damage}

An in-vitro model of sepsis-induced myocardial injury model was constructed using LPS-induced H9C2 cardiomyocytes. The model was treated with different concentrations of Deh to further investigate the effects of Deh on sepsis-mediated myocardial injury. CCK8 and BrdU assays were carried out to detect the viability of cells in different groups. The results demonstrated that, compared with that in the control group, the cell viability in the Deh group didn't significantly alter, while in LPS group was considerably reduced. Deh enhanced the viability in a dose-dependent manner compared with that in the LPS group (Figures 3A-C). Subsequently, western blot was performed to investigate the effects of Deh on the expression levels of apoptosis-related proteins, such as Bax, Caspase3 and Bcl2. The results indicated that with the increase in Deh 


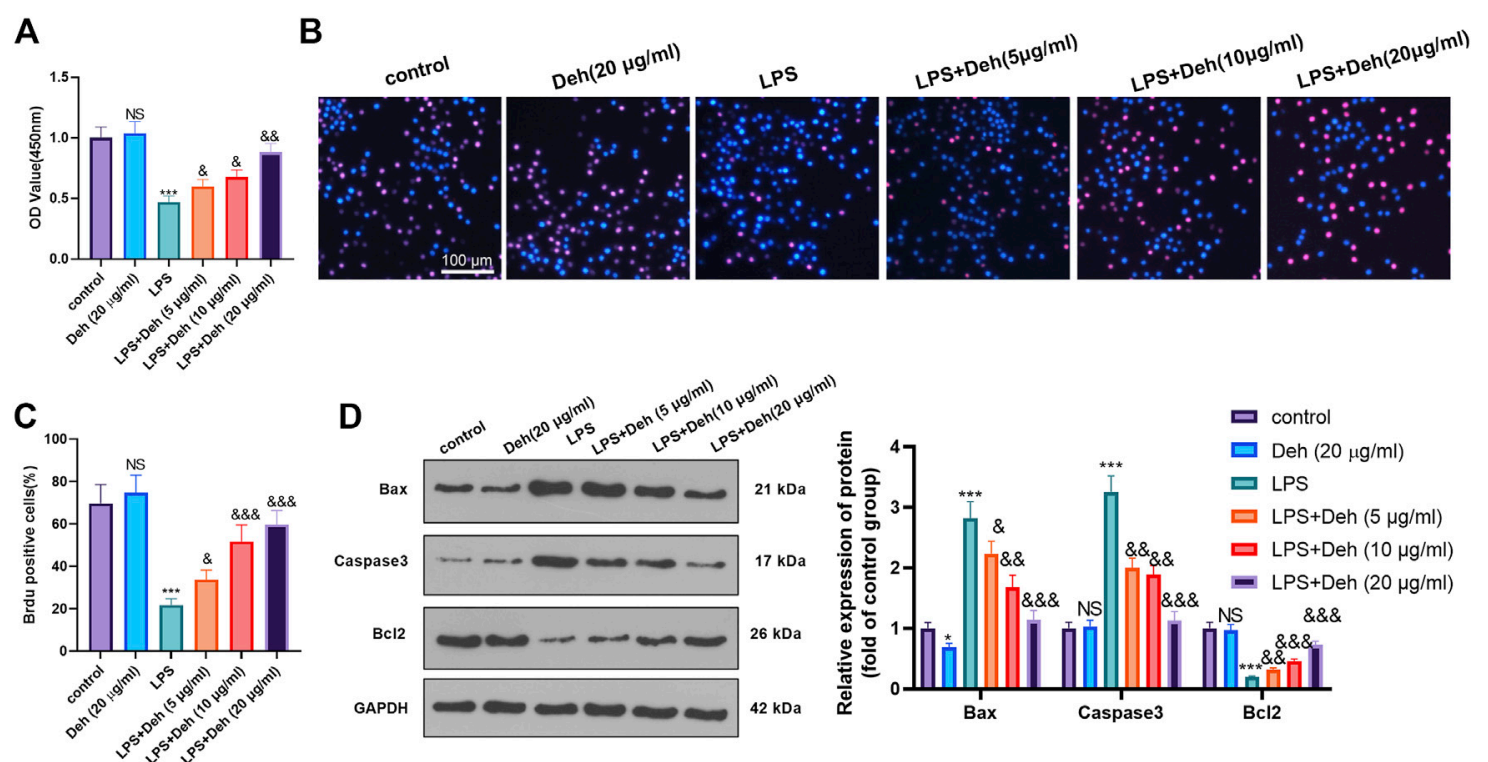

E $\quad F$

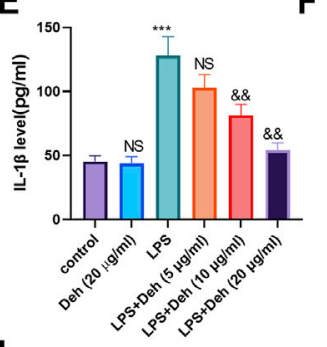

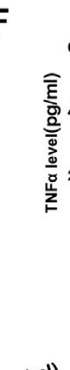

G

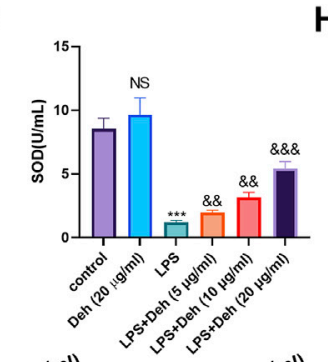

H

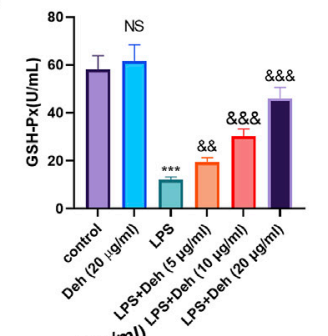

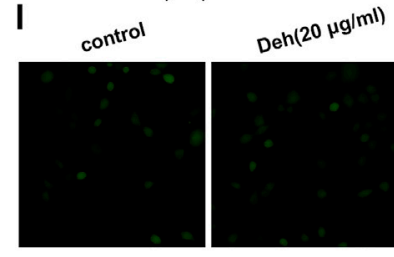
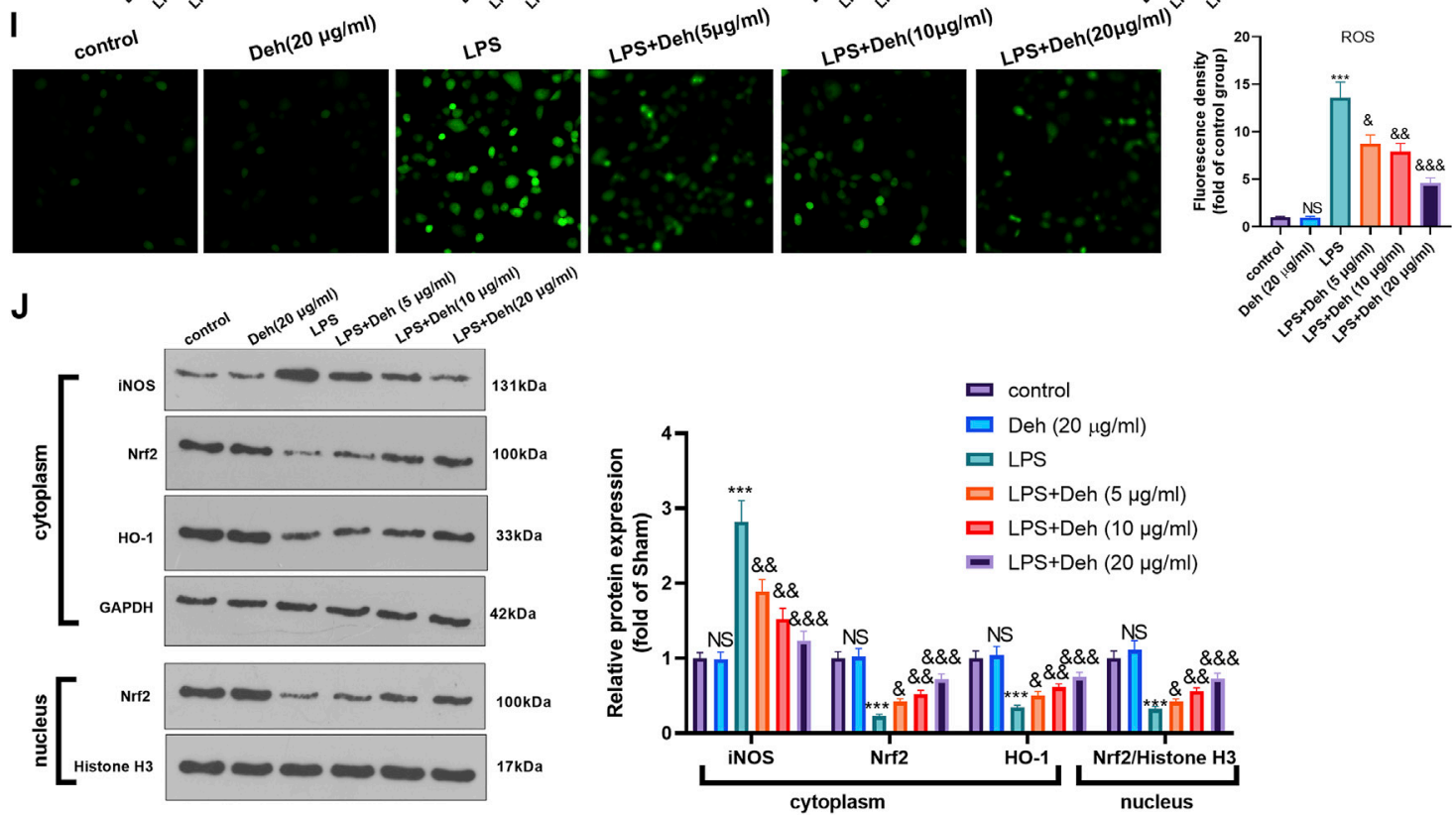

FIGURE 3 | Deh attenuated LPS-mediated H9C2 cell damage. The H9C2 cardiomyocytes were treated with LPS (10 $\mu \mathrm{g} / \mathrm{ml})$ and/or Deh (5-20 $\mu \mathrm{g} / \mathrm{ml})$ for $24 \mathrm{~h}$ (A, B) CCK8, and BrdU assay were taken to detect the cell viability of each group. (C) The rate of BrdU positive cells (red)/nucleus (blue) was calculated. (D) Western blot was performed for the detection of Bax, Caspase3 and Bcl2 expressions in cardiomyocytes. (E, F) ELISA method was employed to evaluate IL-1 $\beta$ and TNF $\alpha$ levels in the culture medium of each group. $(\mathbf{G}, \mathbf{H})$ The SOD and GSH-PX detection kits were applied to detect SOD $(\mathbf{G})$ and GSH-PX $\mathbf{( H )}$ levels in the culture medium of each group. I. The ROS level in H9C2 cells were evaluated using the DCFDA/H2DCFDA-Cellular ROS Assay Kit. J. The protein level of NOS, Nrf2/HO-1 in the whole cell or nucleus of heart was detected by western blot. NS $p>0.05,{ }^{*} p<0.05,{ }^{\star \star *} p<0.001$ (vs. control group); $\& p<0.05, \& \& p<0.01, \& \& \& p<0.001$ (vs. LPS group). $N=3$. 
A

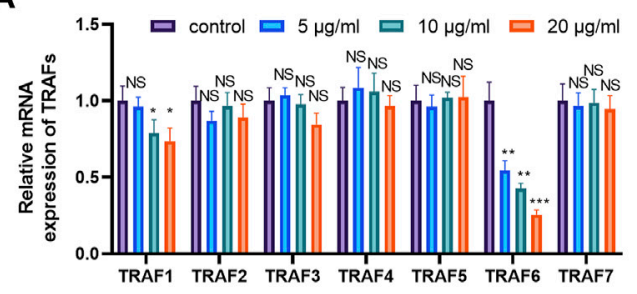

C

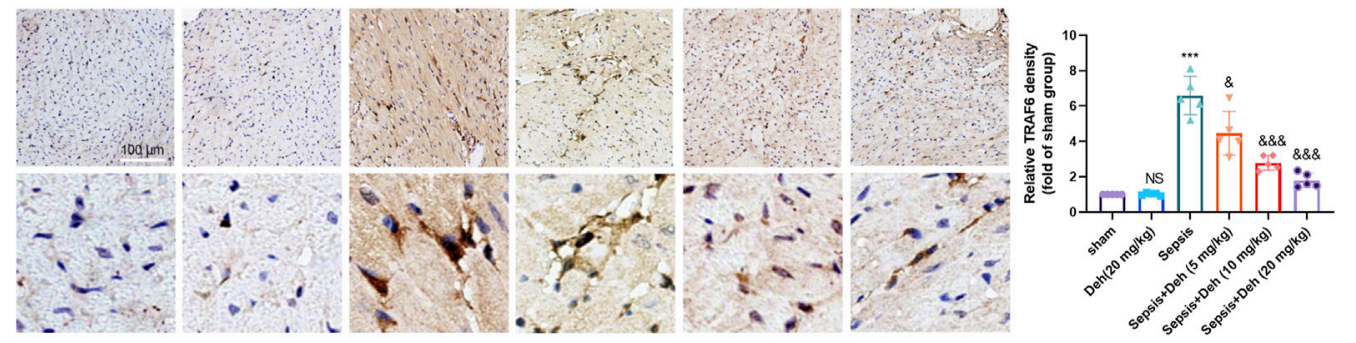

B

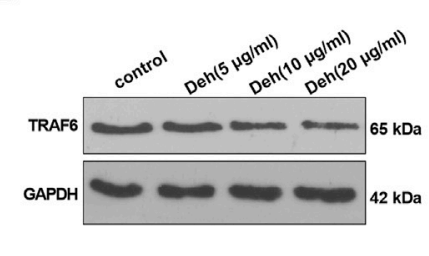

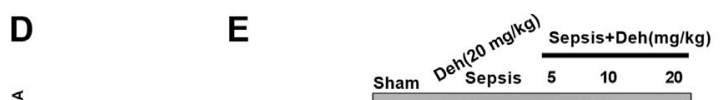
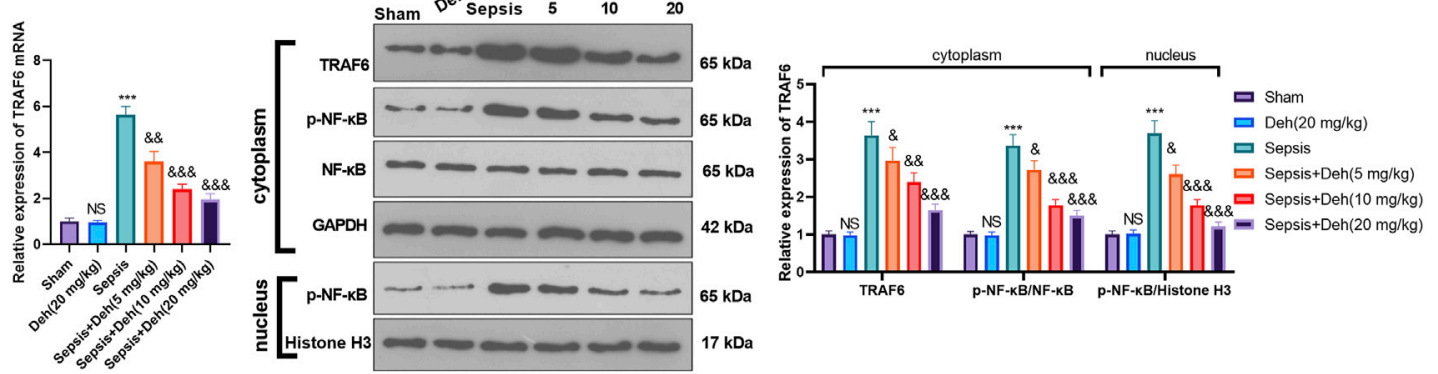

F $\quad$ G
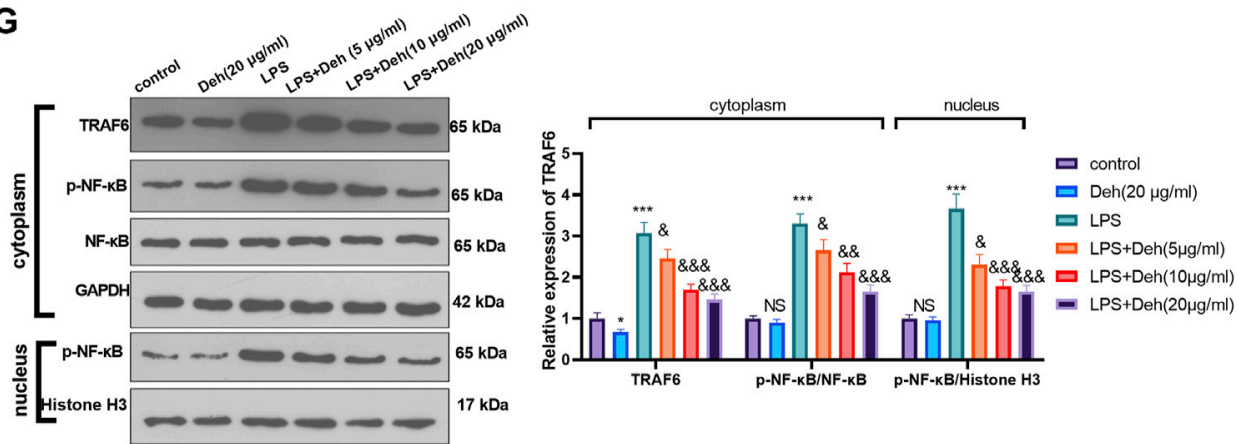

FIGURE 4 | Deh attenuated TRAF6/NF-кB expression. (A) RT-PCR was used for evaluating TRAF1 7 in H9C2 cells treated with Deh (5-20 $\mu \mathrm{g} / \mathrm{ml}$ ) for 24 h. (B) Western blot was performed to examine TRAF6 in H9C2 cells. (C) Immunohistochemistry was used to evaluate the expression of TRAF6 in the mouse myocardial tissues of each group, $\mathrm{N}=5$. (D, E) RT-PCR and Western blot was used for evaluating TRAF6 and p-NF- $\mathrm{BB}$ expressions in the myocardial tissues of each group, $\mathrm{N}=5$. (F, $\mathbf{G})$ RT-PCR and Western blot was used for evaluating TRAF6 and $p-N F-\kappa B$ expressions in H9C2 cardiomyocytes, $N=3$. NS $p>0.05,{ }^{*} p<0.05,{ }^{\star \star} p<0.01,{ }^{\star \star *} p<$ 0.001 (vs. control or sham group); \& $p<0.05, \& \& p<0.01, \& \& \& p<0.001$ (vs. LPS group).

concentration, the expression levels of the pro-apoptotic proteins Bax and Caspase 3 were downregulated, whereas the expression levels of the anti-apoptotic protein $\mathrm{Bcl} 2$ were upregulated (Figure 3D). Furthermore, the levels of inflammatory factors (IL- $1 \beta$ and TNF $\alpha$ ) and antioxidant factors (SOD and GSH-PX) were measured via ELISA. The results revealed that Deh reduced IL- $1 \beta$ and TNFa levels in LPS-induced H9C2 cells in a dose- dependent manner, and increased SOD and GSH-PX levels (Figures 3E-H). The ROS level in H9C2 cells was detected. The result indicated that LPS remarkedly promoted ROS level, and Deh attenuated ROS generation in a dose-dependently (Figure 3I). Western blot was conducted to evaluate the protein level of $\mathrm{Nrf} 2 / \mathrm{HO}-1$ and iNOS in the $\mathrm{H} 9 \mathrm{C} 2$ cells. It was found that iNOS was significantly increased in the LPS 
group, while Nrf2 and HO-1 in the whole cell, and Nrf2 in the nucleus were all repressed (compared with control group, Figure 3J). Interestingly, the Deh administration significantly repressed iNOS, and promoted Nrf2, HO-1 and nucleus Nrf2 levels (compared with LPS group, Figure 3J). The aforementioned results indicated that Deh attenuated LPSmediated H9C2 cell damage via repressing inflammation and oxidative stress in a dose-dependent manner.

\section{Deh Attenuates Activation of the TRAF6/ NF-кB Signaling Pathway}

The mechanism by which Deh attenuated sepsis-induced myocardial injury was investigated further. First, RT-PCR was used to detect TRAFs (including TRAF1, TRAF2, TRAF3, TRAF4, TRAF5, TRAF6, and TRAF7) in H9C2 cells treated with Deh $(5-20 \mu \mathrm{g} / \mathrm{ml})$. It was found that it was TRAF6, not the other TRAFs, were significantly inhibited with Deh treatment (Figure 4A). The result of western blot also indicated that Deh attenuated TRAF6 protein level in H9C2 cells (Figure 4B). Immunohistochemistry was performed to examine the level of TRAF6 in myocardial tissues. It was found that sepsis induced significant promotion of TRAF6 in the heart, and Deh mitigated TRAF6 upregulation in sepsis mice (Figure 4C). Subsequently, the relative levels of TRAF6 and p-NF- $\kappa$ B in myocardial tissues and $\mathrm{H} 9 \mathrm{C} 2$ cells were evaluated using RT-PCR or western blot. It was revealed that TRAF6, p-NF- $\kappa$ B (in the whole cell) and nucleus $\mathrm{p}-\mathrm{NF}-\kappa \mathrm{B}$ were upregulated in both sepsis mouse myocardial tissues and LPS-induced H9C2 cells. Deh treatment decreased TRAF6 and p-NF- $\mathrm{B}$ levels in a dosedependent manner (Figures 4D-G). These results suggest that Deh attenuates TRAF6/NF- $\kappa$ B signaling pathway activation in sepsis myocardial injury model.

\section{Inhibition of TRAF6 Attenuates Deh-Mediated Myocardial Protection Against LPS}

To examine whether Deh prevents sepsis-mediated myocardial injury via the TRAF6/NF- $\mathrm{BB}$ signaling pathway, LPS-induced H9C2 cardiomyocytes were treated with TRAF6 inhibitor C25140. CCK8 and BrdU assays were performed to detect cell proliferation in different groups, and it was revealed that, compared with the LPS group, the cell viability was enhanced following C25-140 intervention, while no significant difference was observed in the LPS + C25-140 + Deh group compared with the LPS + C25-140 group (Figures 5A,B). Additionally, C25-140 inhibited Bax and Caspase 3 expression and decreased $\mathrm{Bcl} 2$ expression in LPS-induced cells, while no significant changes were observed with the supplement of Deh in LPS + C25-140treated cells (Figure 5C). Furthermore, C25-140 inhibited IL-1 $\beta$, TNFa, and ROS expression and enhanced SOD and GSH-PX expression in LPS-induced cells. However, the cells treated with the combination of C25-140 and Deh exhibited no significant difference in the expression levels of the inflammatory factors and oxidative factors compared with cells in the LPS + C25-140 group (Figures 5D-I). Western blot was applied to detect the levels of
iNOS, Nrf2, HO-1, TRAF6 and p-NF- $\kappa$ B in LPS-induced H9C2 cardiomyocytes. It was revealed that C25-140 limited iNOS, TRAF6 and p-NF- $\kappa$ B levels, while promoted Nrf2 and HO-1 expression. However, no significant difference was observed in the relative levels of the above proteins in LPS-induced H9C2 cardiocytes after the addition of Deh $(p>0.05$, vs. LPS + C25-140 group, Figures 5J,K). The aforementioned results suggest that inhibition of TRAF6 attenuates Deh-mediated myocardial protective effects.

\section{Inhibition of NF-kB Attenuates Deh-Mediated Myocardial Protection Against LPS}

Furtermore, LPS-induced H9C2 cells were dealt with the NF- $\kappa \mathrm{B}$ inhibitor BAY 11-7082. The proliferation of H9C2 cells was determined by CCK8 and BrdU assays. It was found that BAY11-7082 relieved LPS-mediated cell proliferation decline. However, the combined treatment of BAY 11-7082 and Deh exerted no additional effects on $\mathrm{H} 9 \mathrm{C} 2$ cell proliferation $(p>$ 0.05 vs. LPS + BAY 11-7082 group, Figures 6A,B). The detection of apoptosis-related proteins revealed that BAY 117082 inhibited Bax and Caspase 3 expression in LPS-treated H9C2 cells, Bcl2 expression in LPS-induced cells was promoted. The addition of Deh in LPS + BAY 11-7082 group had no significant changes on those proteins (Figure 6C). The inflammatory cytokines, including IL-1 $\beta$ and $\mathrm{TNFa}$, and ROS expression were all repressed by BAY 11-7082 (vs. LPS group), and BAY 11-7082 also enhanced SOD and GSH-PX expression in LPS-induced cells. However, the cells treated with the combination of BAY 11-7082 and Deh exhibited no significant difference in the expression levels of the inflammatory factors and oxidative factors compared with cells in the LPS + BAY 11-7082 group (Figures 6D-I). The levels of iNOS, Nrf2, HO-1, TRAF6 and p-NF- $\kappa$ B in LPS-induced H9C2 cardiomyocytes were evaluated by Western blot. It was shown by the results that BAY 11-7082 suppressed iNOS, and p-NF- $\kappa \mathrm{B}$ levels, while promoted Nrf2 and $\mathrm{HO}-1$ expression. However, no significant difference was observed in the relative levels of the above proteins in LPS-induced H9C2 cells after the addition of Deh ( $p>0.05$, vs. LPS + BAY 11-7082 group, Figures 6J,K). Collectively, those data suggested that Deh relieved LPS-mediated inflammatory, oxidative and $\mathrm{H} 9 \mathrm{C} 2$ cell apoptosis dependently through inhibiting NF- $\mathrm{B}$ pathway.

\section{DISCUSSION}

The present study explored the therapeutic effects of Deh in an LPS-induced sepsis model. The present data indicated that Deh ameliorated myocardial injury by modulating inflammation and oxidative stress through repressing TRAF6-mediated NF- $\kappa B$ pathway.

Sepsis is a systemic inflammatory response syndrome, and is caused by severe infections of various sources. Multi-organ functional injury is a major complication of sepsis, among which myocardial injury and cardiac failure are the most common complications of sepsis and are also one of the major 


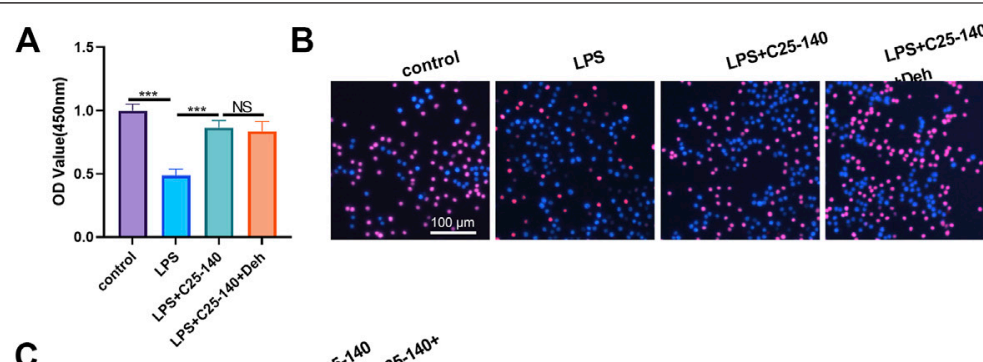

C

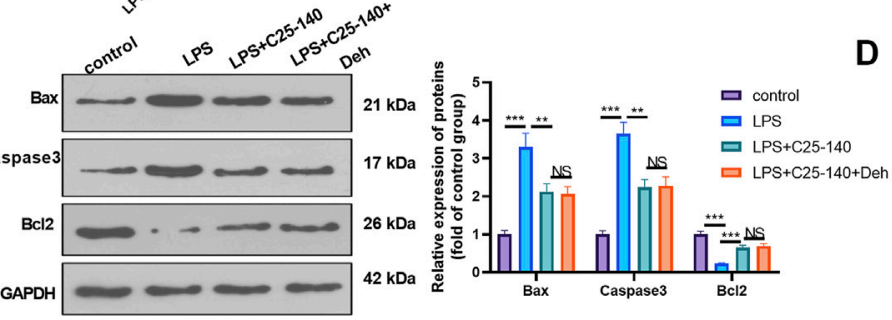

D

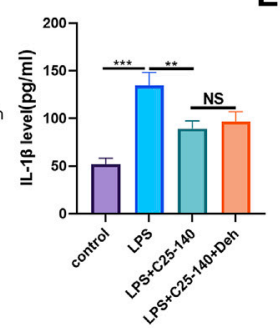

$E$

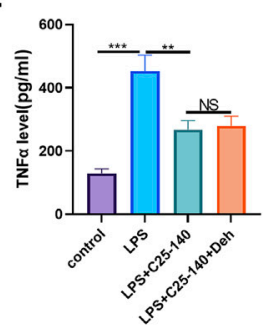

$\mathbf{F}$

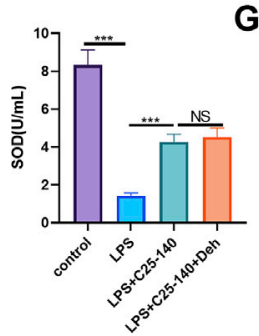

G

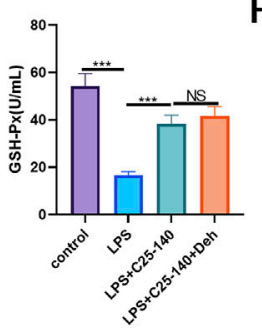

H
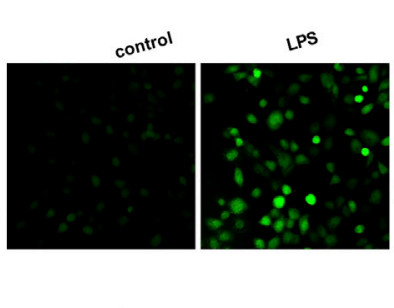

$L P S+C 25-140$

$L P S+C 25-140$
$+D e^{-h}$

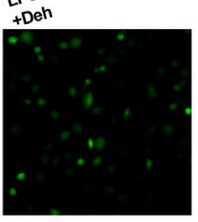

J
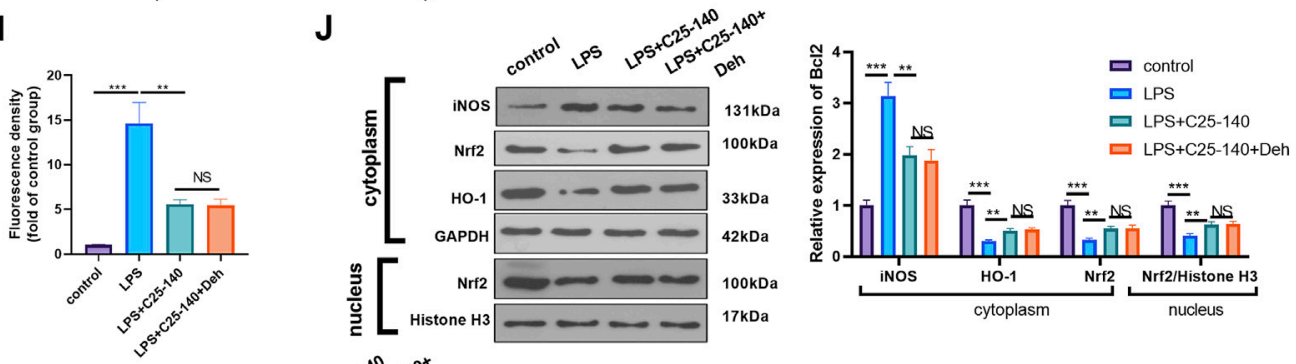

K
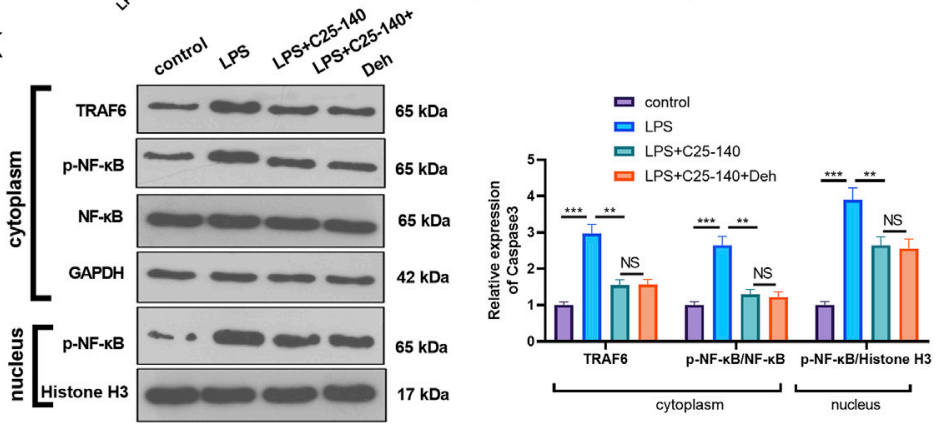

FIGURE 5 | Inhibition of TRAF6 attenuated LPS-mediated myocardial injury. The H9C2 cardiomyocytes were pretreated with C25-140 (5 $\mu$ M, an inhibitor of TRAF6) for $2 \mathrm{~h}$ and then treated with LPS $(10 \mu \mathrm{g} / \mathrm{ml})$ and Deh $(10 \mu \mathrm{g} / \mathrm{ml})$ for $24 \mathrm{~h}$ (A, B) CCK8, and BrdU assay were taken to detect the cell viability of each group. The rate of BrdU positive cells (red)/nucleus (blue) was calculated. (C) Western blot was performed for the detection of Bax, Caspase3 and Bcl2 expressions in cardiomyocytes. (D, E) ELISA method was employed to evaluate IL-1 $\beta$ and TNFa levels in the culture medium of each group. (F, G) The SOD and GSH-PX detection kits were applied to detect SOD (G) and GSH-PX (H) levels in the culture medium of each group. (H, I). The ROS level in H9C2 cells were evaluated using the DCFDA/H2DCFDA - Cellular ROS Assay Kit. (J, K). The protein level of iNOS, Nrf2/HO-1, TRAF6, and p-NF-kB in the whole cell or nucleus of heart was detected by western blot. nsP $>0.05,{ }^{\star \star} p<0.01,{ }^{* \star *} p<0.001 . \mathrm{N}=3$.

risk factors affecting the prognosis of severe sepsis (Frencken et al., 2018). Currently, research focuses on how to minimize myocardial injury in severe sepsis and protect cardiac function
(Kakihana et al., 2016, Ito, Nakahara, Yamaguchi, Yasuda; Fernandes et al., 1999). With the increased researches on myocardial injury, multiple drugs have been found effective 


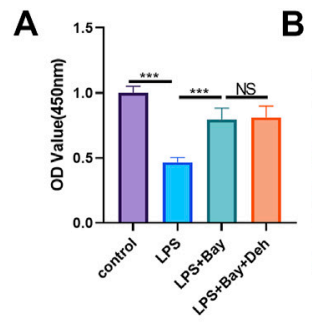

B
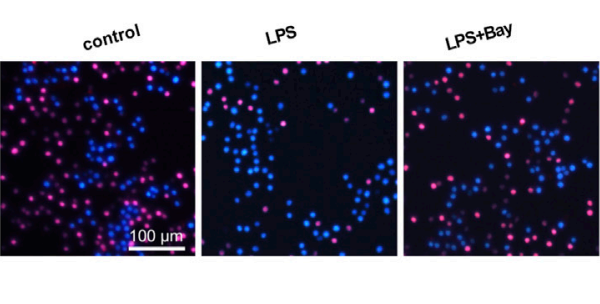

C
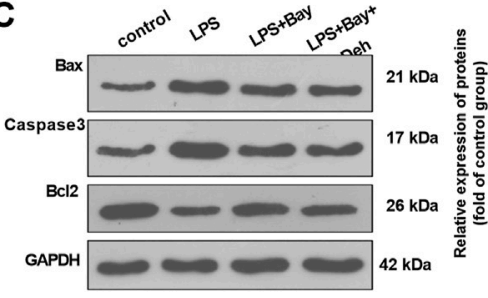

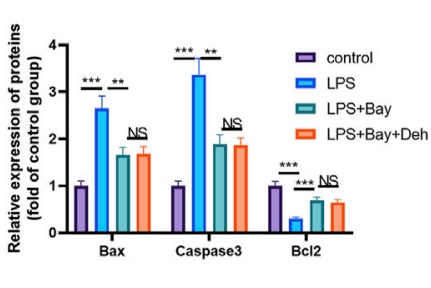

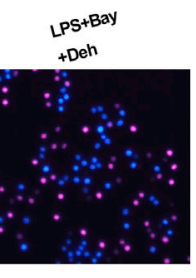

D

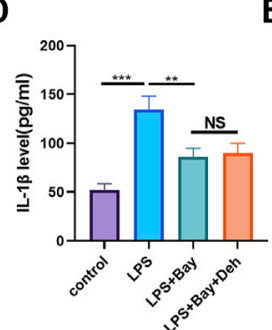

E
F

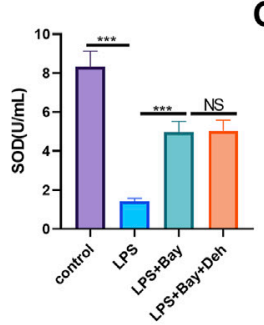

I

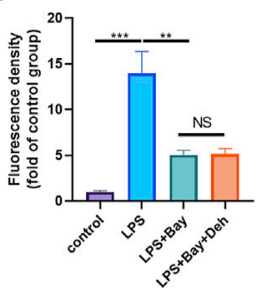

G

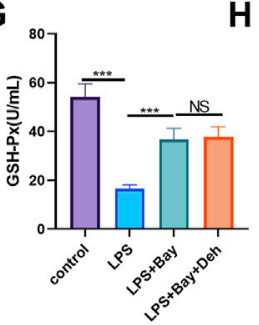

H
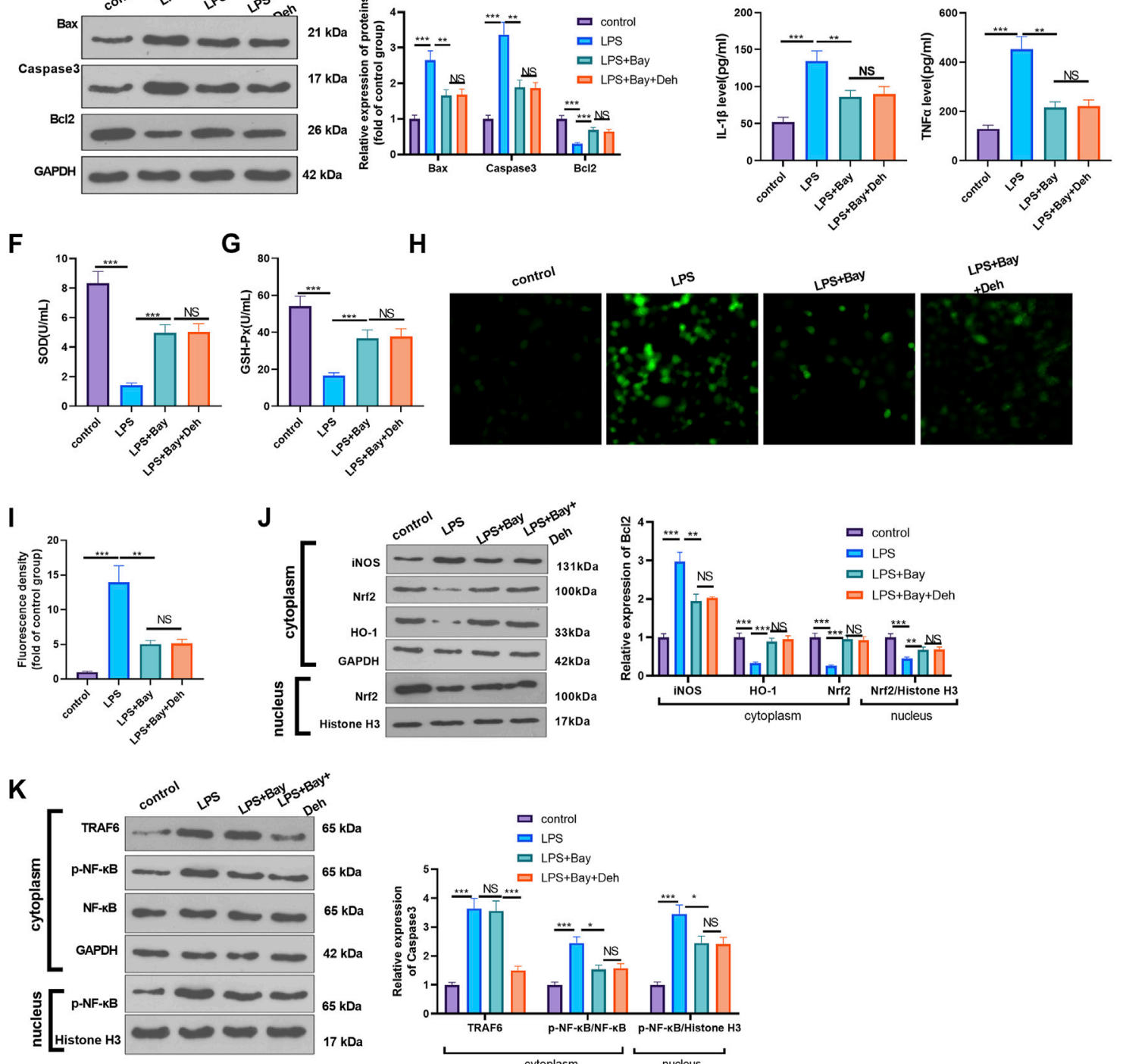

FIGURE 6 | Inhibition of NF- $\mathrm{kB}$ attenuated LPS-mediated myocardial injury. The H9C2 cardiomyocytes were pretreated with BAY $11-7082$ (BAY, 1 $\mu$ M, an inhibitor of NF-kB) for $2 \mathrm{~h}$ and then treated with LPS $(10 \mu \mathrm{g} / \mathrm{ml})$ and Deh $(10 \mu \mathrm{g} / \mathrm{ml})$ for $24 \mathrm{~h}$ (A, B) CCK8, and BrdU assay were taken to detect the cell viability of each group. The rate of BrdU positive cells (red)/nucleus (blue) was calculated. (C) Western blot was performed for the detection of Bax, Caspase3 and Bcl2 expressions in cardiomyocytes. (D, E) ELISA method was employed to evaluate IL-1 $\beta$ and TNFa levels in the culture medium of each group. (F, G) The SOD and GSH-PX detection kits were applied to detect SOD (G) and GSH-PX (H) levels in the culture medium of each group. H-I. The ROS level in H9C2 cells were evaluated using the DCFDA/H2DCFDA - Cellular ROS Assay Kit. (J, K). The protein level of iNOS, Nrf2/HO-1, TRAF6, and p-NF-kB in the whole cell or nucleus of heart was detected by western blot. nsP $>0.05,{ }^{*} p<0.05,{ }^{* *} p<0.01,{ }^{* * *} p<0.001 . \mathrm{N}=3$.

against it via repressing inflammation, and oxidative stress. For example, salidroside can exert a protective effect on LPS-induced myocardial injury by inhibiting the reactive oxygen species- mediated PI3K/AKT/mTOR signaling pathway (Chen et al., 2017). Furthermore, oxymatrine inhibits the Janus kinase 2/ STAT3 signaling pathway and decreases the expression levels 


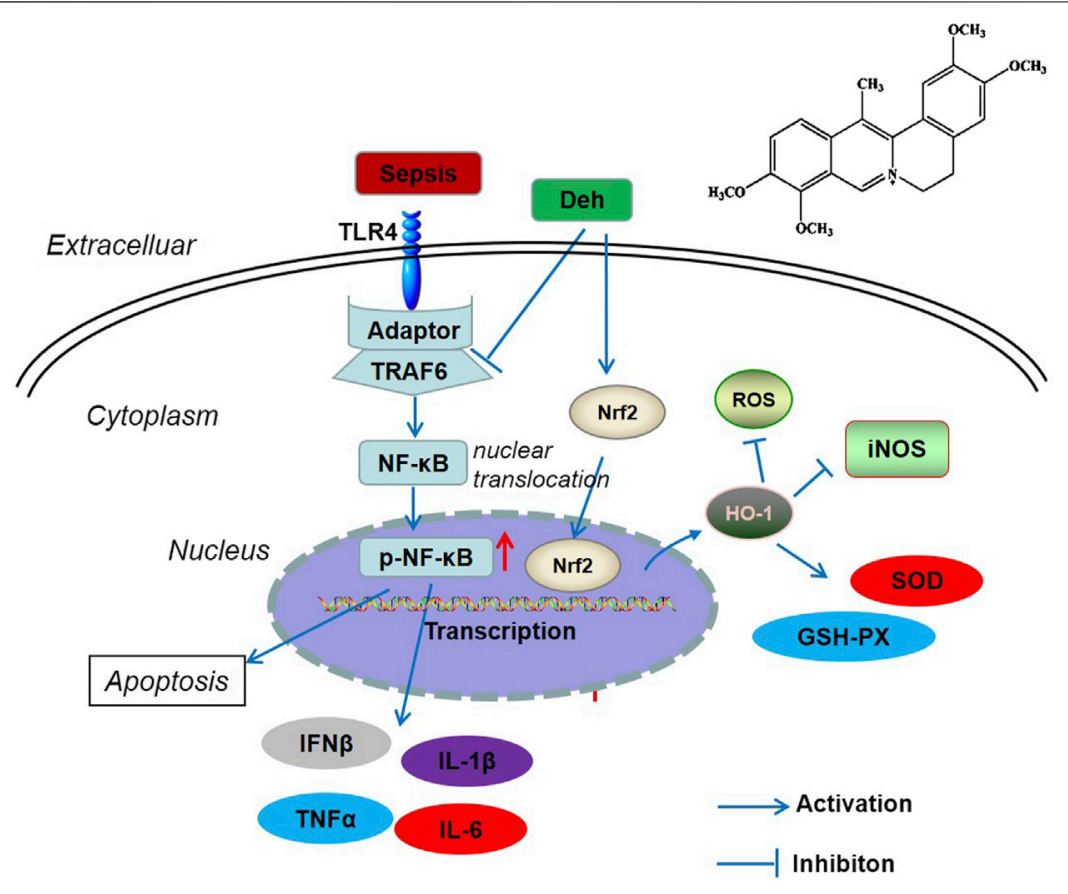

FIGURE 7 | The scheme of Deh mediated myocardial protective effects against sepsis. LPS was recognized by TLR4 and then activated TRAF6 mediated NF- $\kappa B$ phosphorylation. The phosphorylated NF- $\mathrm{kB}$ translocated from the cytoplasm into the nucleus and promoted the transcription of inflammatory factors. Once Deh was administered, TRAF6 was in inhibited and the NF-kB mediated inflammation was also attenuated. Moreover, Deh treatment promoted Nrf2 nucleus translocation. Nrf2 promoted HO-1 expression, which induced enhanced anti-oxidative meidators (including SOD, GSH-PX) and inhibited iNOS and ROS level.

of pro-inflammatory factors IL-1 $\beta$ and TNFa, thereby alleviating myocardial injury caused by septic shock (Zhang et al., 2013). Delta opioid receptor agonists can alleviate LPS-induced myocardial ultrastructure damage in mice, protect against myocardial insufficiency and improve the survival rate of mice (Zhao et al., 2017). Moreover, many traditional Chinese medicines have been found with anti-inflammatory and antioxidant effects (Shingnaisui et al., 2018). Hence, it is of great significance to investigate the protective role of traditional Chinese medicine extracts in sepsis-mediated myocardial injury.

Deh is an important bioactive component of the Chinese herb Corydalis ambigua. This herb has a wide range of therapeutic effects in a variety of diseases, including cancer associated pain (Huo et al., 2018), depression (Jin et al., 2019), melanoma (Hu et al., 2019), and so on. For example, Deh stimulates MAPK activation of $\mathrm{p} 38$ protein and enhances the interaction between MyoD and E protein, thus leading to the activation of MyoD and myoblast differentiation, and enhancing the regeneration ability of injured muscle stem cells (Yoo et al., 2016). Yin et al Yin et al. (2016) reported that Deh could reduce the formalin-induced pain response in mice and decreased the expression levels of IL-1 $\beta$, IL6 and other inflammatory factors. Ishiguro et al Ishiguro et al. (2011) revealed that Deh not only inhibited the increase of mitochondrial membrane potential and ATP depletion in LPSstimulated macrophages, but also inhibited the increase in IL-1 $\beta$ and IL-6 concentration in LPS-induced macrophage culture medium. The present study revealed that Deh enhanced viability and inhibited apoptosis of cardiomyocytes induced by LPS in vitro or Escherichia coli in mice. Furthermore, Deh attenuated IL-1 $\beta$ and TNFa levels in plasma and cardiomyocyte culture medium in a dose-dependent manner and increased the expression levels of SOD and GSH-PX. These results suggest that Deh attenuates sepsis-mediated myocardial injury via anti-inflammation and anti-oxidative stress.

TNF receptor-associated factor family members mainly include TRAF1-7. Interestingly, previous studies have found that the TRAFs, including TRAF1 (Bin et al., 2019), TRAF2 (Etemadi et al., 2015), TRAF3 (Lei et al., 2021), TRAF4 (Li et al., 2020), TRAF5 (Sun et al., 2021), TRAF6 (Min et al., 2018) and TRAF7 (Zotti et al., 2011) all have a role in modulating NF- $\kappa B$ activity. The upregulation of TRAFs also makes a role during sepsis progression. For example, LPS and TNFalpha increased nuclear translocation of NF- $\kappa \mathrm{B}$ p65 dependently throough enhancing the steady state of TRAF1 mRNA in neutrophil (PMN) (Nolan et al., 2000). In another study, inflammatory preconditioning (InP) induces TLR9 translocation from the neutrophil cytosol to the membrane. Thus, TLR9 binds to Cav-1 and activates MyD88-mediated TRAF3 and IRF3 signal transduction (Yang et al., 2019). Presently, we detected all of the seven TRAFs in H9C2 cells treated by different doses of Deh. It was found that TRAF6 was significantly downregulated by Deh. Interestingly, Previous studies (Wullaert et al., 2007; Chen et al., 2010) have reported that LPS, a ligand of TLR4, activates the complex of IL-1 $\beta$ receptor-associated kinases and TRAF6 after 
binding with it, and TRAF6 releases TNFa, IL-6 and other proinflammatory factors by inducing the nucleus translocation of

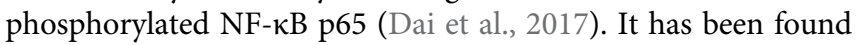
that blocking TRAF6 limits the inflammatory response-mediated by intracranial hemorrhage (Yang et al., 2020), Alzheimer's disease (Wang et al., 2018), and Salmonella typhimurium infection (Min et al., 2017). Furthermore, we explored the underlying mechanism of TAF6/NF- $\kappa \mathrm{B}$ pathway in sepsisinduced myocardial damage. The present study revealed that sepsis promoted TRAF6 expression and the nucleus translocation of phosphorylated NF- $\kappa$ B p65. Deh treatment decreased the levels of TRAF6 and p-NF- $\kappa$ B p65 in a dose-dependent manner. Both of the TRAF6 inhibitor of $\mathrm{C} 25-140$ and NF- $\kappa$ B inhibitor BAY 117082 relieved LPS-mediated injury on $\mathrm{H} 9 \mathrm{C} 2$ cells, while the addition of Deh gained no more protective effects. Those data suggests that Deh has a protective effect on LPS-induced myocardial cell injury dependently through inhibiting the TRAF6/NF- $\kappa$ B signaling pathway.

Oxidative stress plays a vital role in sepsis-induced organ injury (Nadeem et al., 2021). Those overproduced reactive species and/or free radicals, including nitric oxide (NO), peroxynitrite $\left(\mathrm{ONOO}^{-}\right)$, superoxide $\left(\mathrm{O}_{2}{ }^{-}\right)$, hydrogen peroxide $\left(\mathrm{H}_{2} \mathrm{O}_{2}\right)$, and hydroxyl radical $(\mathrm{OH})$, are the results of impairment of oxygen utilization by cells and limited delivery of oxygen to tissues (Prauchner, 2017). Nuclear factor erythroid 2-related factor 2 (Nrf2), a member of the Cap-n-Collar family of basic leucine zipper proteins, is crucial in antioxidant defense via controlling the basal and induced expression of an array of antioxidant response elementdependent genes [such as heme oxygenase 1 (HO-1)] in both physiological and pathophysiological environment (Ma, 2013; Mei et al., 2020). In addition, the activation of NF- $\kappa B$ pathway or ROS promotes the expression of inducible nitric oxide synthase (iNOS), which is inhibited by the upregulation of Nrf2/HO-1 pathway (Dijkstra et al., 2004; Shen et al., 2021). Here, we found that sepsis led to enhanced iNOS level and reduced Nrf2/HO-1 expression in cardiomyocytes. While all of TRAF6 inhibitor C25-140, NF- $\kappa$ B inhibitor BAY 11-7082 and

\section{REFERENCES}

Bin, W., Ming, X., and Wen-Xia, C. (2019). TRAF1 Meditates Lipopolysaccharide-Induced Acute Lung Injury by up Regulating JNK Activation. Biochem. Biophysical Res. Commun. 511 (1), 49-56. doi:10.1016/j.bbrc.2019.01.041

Chen, F., He, S., Qiu, R., Pang, R., Xu, J., and Dong, J. (2010). Influence of Silencing TRAF6 with shRNA on LPS/TLR4 Signaling In Vitro. J. Huazhong Univ. Sci. Technol. [Med. Sci. 30, 278-284. doi:10.1007/s11596-010-0343-6

Chen, L., Liu, P., Feng, X., and Ma, C. (2017). Salidroside Suppressing LPS-Induced Myocardial Injury by Inhibiting ROS-Mediated PI3K/Akt/mTOR Pathway In Vitro and In Vivo. J. Cel. Mol. Med. 21, 3178-3189. doi:10.1111/jcmm.12871

Dai, J.-P., Wang, Q.-W., Su, Y., Gu, L.-M., Zhao, Y., Chen, X.-X., et al. (2017). Emodin Inhibition of Influenza A Virus Replication and Influenza Viral Pneumonia via the Nrf2, TLR4, p38/JNK and NF-kappaB Pathways. Molecules 22 (10), 1754. doi:10.3390/molecules22101754

Dijkstra, G., Blokzijl, H., Bok, L., Homan, M., van Goor, H., Nico Faber, K., et al. (2004). Opposite Effect of Oxidative Stress on Inducible Nitric Oxide Synthase and Haem Oxygenase-1 Expression in Intestinal Inflammation: Anti-
Deh treatments reduced iNOS level and enhanced Nrf2 expression (both in the whole cell and nucleus). Therefore, we believed that Deh has anti-oxidative stress effects via activating Nrf2/HO-1 pathway.

In conclusion, the present study revealed that Deh attenuated sepsis-mediated myocardial injury. By inhibiting the activation of the TRAF6/NF- $\kappa$ B signaling pathway and activating Nrf2/HO-1 pathway, Deh reduced the release of pro-inflammatory factors and increased the levels of antioxidant stress factors (Figure 7). The present study provides novel insights for the treatment of sepsis-mediated myocardial injury. However, further experiments are required to determine the mechanisms of Deh-mediated myocardial protective effects.

\section{DATA AVAILABILITY STATEMENT}

The raw data supporting the conclusions of this article will be made available by the authors, without undue reservation.

\section{ETHICS STATEMENT}

The animal study was reviewed and approved by the Ethics Committee of the Shanxi Cancer Hospital.

\section{AUTHOR CONTRIBUTIONS}

YDL and $\mathrm{ZH}$ wrote the paper and performed the experiments. PZ analyzed the statistic. ZYH conceived and designed the experiments. All authors read and approved the final manuscript.

\section{FUNDING}

This work was supported by National Natural Science Foundation of China Youth Program (No. 81900455).

inflammatory Effect of Carbon Monoxide. J. Pathol. 204 (3), 296-303. doi:10.1002/path.1656

Etemadi, N., Chopin, M., Anderton, H., Tanzer, M. C., Rickard, J. A., Abeysekera, W., et al. (2015). TRAF2 Regulates TNF and NF-Kb Signalling to Suppress Apoptosis and Skin Inflammation Independently of Sphingosine Kinase 1. Elife 4, e10592. doi:10.7554/elife.10592

Fernandes, C. J., Akamine, N., and Knobel, E. (1999). Cardiac Troponin: a New Serum Marker of Myocardial Injury in Sepsis. Intensive Care Med. 25, 1165-1168. doi:10.1007/s001340051030

Frencken, J. F., Donker, D. W., Spitoni, C., Koster-Brouwer, M. E., Soliman, I. W., Ong, D. S. Y., et al. (2018). Myocardial Injury in Patients with Sepsis and its Association with Long-Term Outcome. Circ. Cardiovasc. Qual. Outcomes 11, e004040. doi:10.1161/circoutcomes.117.004040

Ha, T., Hua, F., Liu, X., Ma, J., McMullen, J. R., Shioi, T., et al. (2008). Lipopolysaccharide-induced Myocardial protection against Ischaemia/ reperfusion Injury Is Mediated through a PI3K/Akt-dependent Mechanism. Cardiovasc. Res. 78, 546-553. doi:10.1093/cvr/cvn037

Hennessy, E. J., Parker, A. E., and O’Neill, L. A. J. (2010). Targeting Toll-like Receptors: Emerging Therapeutics? Nat. Rev. Drug Discov. 9, 293-307. doi: $10.1038 / \operatorname{nrd} 3203$ 
Hochstadt, A., Landesberg, Y. G., and Giora, L. (2011). Myocardial Dysfunction in Severe Sepsis and Septic Shock: More Questions Than Answers? J. Cardiothorac. Vasc. Anesth. 25, 526-535. doi:10.1053/j.jvca.2010.11.026

Hu, H., Dong, Z., Wang, X., Bai, L., Lei, Q., Yang, J., et al. (2019). Dehydrocorydaline Inhibits Cell Proliferation, Migration and Invasion via Suppressing MEK1/2-Erk1/2 cascade in Melanoma. Ott 12, 5163-5175. doi:10.2147/ott.s183558

Huo, W., Zhang, Y., Liu, Y., Lei, Y., Sun, R., Zhang, W., et al. (2018). Dehydrocorydaline Attenuates Bone Cancer Pain by Shifting Microglial M1/ M2 Polarization toward the M2 Phenotype. Mol. Pain 14, 1744806918781733. doi:10.1177/1744806918781733

Innocenti, F., Palmieri, V., Stefanone, V. T., Donnini, C., D’Argenzio, F., Cigana, M., et al. (2020). Epidemiology of Right Ventricular Systolic Dysfunction in Patients with Sepsis and Septic Shock in the Emergency Department. Intern. Emerg. Med. 15, 1281-1289. doi:10.1007/s11739-020-02325-z

Inoue, J., Gohda, J. T., and Akiyama, Taishin. (2007). Characteristics and Biological Functions of TRAF6. Adv. Exp. Med. Biol. 597, 72-79. doi:10.1007/978-0-38770630-6_6

Ishiguro, K., Ando, T., Maeda, O., Watanabe, O., and Goto, H. (2011). Dehydrocorydaline Inhibits Elevated Mitochondrial Membrane Potential in Lipopolysaccharide-Stimulated Macrophages. Int. Immunopharmacology 11, 1362-1367. doi:10.1016/j.intimp.2011.04.022

Jin, L., Zhou, S., Zhu, S., Lei, S., Du, W., Jiang, H., et al. (2019). Dehydrocorydaline Induced Antidepressant-like Effect in a Chronic Unpredictable Mild Stress Mouse Model via Inhibiting Uptake-2 Monoamine Transporters. Eur. J. Pharmacol. 864, 172725. doi:10.1016/j.ejphar.2019.172725

Kakihana, Y., Ito, T., Nakahara, M., Yamaguchi, K., and Yasuda, T. (2016). Sepsisinduced Myocardial Dysfunction: Pathophysiology and Management. J. Intensive Care 4 (22), 22. doi:10.1186/s40560-016-0148-1

Lei, Y., Cao, X., Xu, W., Yang, B., Xu, Y., Zhou, W., et al. (2021). Rv3722c Promotes Mycobacterium tuberculosis Survival in Macrophages by Interacting with TRAF3. Front Cel Infect Microbiol. 11, 627798. doi:10.3389/fcimb.2021.627798

Lewis, D. H., Chan, D. L., Pinheiro, D., Armitage-Chan, E., and Garden, O. A. (2012). The Immunopathology of Sepsis: Pathogen Recognition, Systemic Inflammation, the Compensatory Anti-inflammatory Response, and Regulatory T Cells. J. Vet. Intern. Med. 26, 457-482. doi:10.1111/j.19391676.2012.00905.x

Li, S., Lu, G., Wang, D., He, J. L., Zuo, L., Wang, H., et al. (2020). MicroRNA-4443 Regulates Monocyte Activation by Targeting Tumor Necrosis Factor Receptor Associated Factor 4 in Stroke-induced Immunosuppression. Eur. J. Neurol. 27 (8), 1625-1637. doi:10.1111/ene.14282

Luo, M., Yan, D., Sun, Q., Tao, J., Xu, L., Sun, H., et al. (2020). Ginsenoside Rg1 Attenuates Cardiomyocyte Apoptosis and Inflammation via the TLR4/NF-kB/ NLRP3 Pathway. J. Cel Biochem. 121, 2994-3004. doi:10.1002/jcb.29556

Ma, Q. (2013). Role of Nrf2 in Oxidative Stress and Toxicity. Annu. Rev. Pharmacol. Toxicol. 53, 401-426. doi:10.1146/annurev-pharmtox-011112140320

Mei, Y., Wang, Z., Zhang, Y., Wan, T., Xue, J., He, W., et al. (2020). FA-97, a New Synthetic Caffeic Acid Phenethyl Ester Derivative, Ameliorates DSS-Induced Colitis against Oxidative Stress by Activating Nrf2/HO-1 Pathway. Front. Immunol. 10, 2969. doi:10.3389/fimmu.2019.02969

Min, Y., Wi, S. M., Shin, D., Chun, E., and Lee, K. Y. (2017). Peroxiredoxin-6 Negatively Regulates Bactericidal Activity and NF-Kb Activity by Interrupting TRAF6-ECSIT Complex. Front. Cel Infect Microbiol. 7 (7), 94. doi:10.3389/ fcimb.2017.00094

Min, Y., Kim, M.-J., Lee, S., Chun, E., and Lee, K.-Y. (2018). Inhibition of TRAF6 Ubiquitin-Ligase Activity by PRDX1 Leads to Inhibition of NFKB Activation and Autophagy Activation. Autophagy 14 (8), 1347-1358. doi:10.1080/15548627.2018.1474995

Nadeem, A., Ahmad, S. F., Al-Harbi, N. O., Ibrahim, K. E., Alqahtani, F., Alanazi, W. A., et al. (2021). Bruton's Tyrosine Kinase Inhibition Attenuates Oxidative Stress in Systemic Immune Cells and Renal Compartment during SepsisInduced Acute Kidney Injury in Mice. Int. Immunopharmacol 90, 107123. doi:10.1016/j.intimp.2020.107123

Nolan, B., Kim, R., Duffy, A., Sheth, K., De, M., Miller, C., et al. (2000). Inhibited Neutrophil Apoptosis: Proteasome Dependent NF-Kb Translocation Is Required for TRAF-1 Synthesis. Shock 14 (3), 290-294. doi:10.1097/ 00024382-200014030-00008
Oyama, J.-i., Blais, C., Jr, Liu, X., Pu, M., Kobzik, L., Kelly, R. A., et al. (2004). Reduced Myocardial Ischemia-Reperfusion Injury in Toll-like Receptor 4-deficient Mice. Circulation 109, 784-789. doi:10.1161/01.cir.0000112575.66565.84

Prauchner, C. A. (2017). Oxidative Stress in Sepsis: Pathophysiological Implications Justifying Antioxidant Co-therapy. Burns 43 (3), 471-485. doi:10.1016/j.burns.2016.09.023

Rocha, M., Herance, R., Rovira, S., Hernández-Mijares, A., and M. Victor, V. (2012). Mitochondrial Dysfunction and Antioxidant Therapy in Sepsis. Iddt 12, 161-178. doi:10.2174/187152612800100189

Shen, K., Jia, Y., Wang, X., Zhang, J., Liu, K., Wang, J., et al. (2021). Exosomes from Adipose-Derived Stem Cells Alleviate the Inflammation and Oxidative Stress via Regulating Nrf2/HO-1 axis in Macrophages. Free Radic. Biol. Med. 165, 54-66. doi:10.1016/j.freeradbiomed.2021.01.023

Shingnaisui, K., Dey, T., Manna, P., and Kalita, J. (2018). Therapeutic Potentials of Houttuynia Cordata Thunb. Against Inflammation and Oxidative Stress: A Review. J. Ethnopharmacology 220, 35-43. doi:10.1016/j.jep.2018.03.038

Song, F., Hou, J., Chen, Z., Cheng, B., Lei, R., Cui, P., et al. (2018). Sphingosine-1phosphate Receptor 2 Signaling Promotes Caspase-11-dependent Macrophage Pyroptosis and Worsens Escherichia coli Sepsis Outcome. Anesthesiology 129 (2), 311-320. doi:10.1097/aln.0000000000002196

Sun, M., Wu, S., Zhang, X., Zhang, L., Kang, S., Qin, Q., et al. (2021). Grouper TRAF5 Exerts Negative Regulation on Antiviral Immune Response against Iridovirus. Fish Shellfish Immunol. 115, 7-13. doi:10.1016/ j.fsi.2021.05.023

Sun, Y., Huang, J., and Song, K. (2015). BET Protein Inhibition Mitigates Acute Myocardial Infarction Damage in Rats via the TLR4/TRAF6/NF-Kb Pathway. Exp. Ther. Med. 10, 2319-2324. doi:10.3892/etm.2015.2789

Wang, S., Zhang, X., Zhai, L., Sheng, X., Zheng, W., Chu, H., et al. (2018). Atorvastatin Attenuates Cognitive Deficits and Neuroinflammation Induced by A $31-42$ Involving Modulation of TLR4/TRAF6/NF-Kb Pathway. J. Mol. Neurosci. 64, 363-373. doi:10.1007/s12031-018-1032-3

Wullaert, A., Verstrepen, L., Van Huffel, S., Adib-Conquy, M., Cornelis, S., Kreike, M., et al. (2007). LIND/ABIN-3 Is a Novel LipopolysaccharideInducible Inhibitor of NF-Kb Activation. J. Biol. Chem. 282, 81-90. doi:10.1074/jbc.m607481200

Yang, Y., Tan, X., Xu, J., Wang, T., Liang, T., Xu, X., et al. (2020). Luteolin Alleviates Neuroinflammation via Downregulating the TLR4/TRAF6/NF-Kb Pathway after Intracerebral Hemorrhage. Biomed. Pharmacother. 126, 110044. doi:10.1016/j.biopha.2020.110044

Yang, Z., Wang, L., Yu, H., Wang, R., Gou, Y., Zhang, M., et al. (2019). Membrane TLR9 Positive Neutrophil Mediated MPLA Protects against Fatal Bacterial Sepsis. Theranostics 9 (21), 6269-6283. doi:10.7150/thno.37139

Yin, Z. Y., Li, L., Chu, S. S., Sun, Q., Ma, Z. L., and Gu, X. P. (2016). Antinociceptive Effects of Dehydrocorydaline in Mouse Models of Inflammatory Pain Involve the Opioid Receptor and Inflammatory Cytokines. Sci. Rep. 6, 27129. doi:10.1038/srep27129

Yoo, M., Lee, S.-J., Kim, Y. K., Seo, D.-W., Baek, N.-I., Ryu, J.-H., et al. (2016). Dehydrocorydaline Promotes Myogenic Differentiation via P38 MAPK Activation. Mol. Med. Rep. 14, 3029-3036. doi:10.3892/mmr.2016.5653

Yuan, X., Juan, Z., Zhang, R., Sun, X., Yan, R., Yue, F., et al. (2020). Clemastine Fumarate Protects against Myocardial Ischemia Reperfusion Injury by Activating the TLR4/PI3K/Akt Signaling Pathway. Front. Pharmacol. 11, 28. doi:10.3389/fphar.2020.00028

Zeuke, S., Ulmer, A. J., Kusumoto, S., Katus, H. A., and Heine, H. (2002). TLR4-mediated Inflammatory Activation of Human Coronary Artery Endothelial Cells by LPS. Cardiovasc. Res. 56, 126-134. doi:10.1016/ s0008-6363(02)00512-6

Zhang, M., Wang, X., Wang, X., Hou, X., Teng, P., Jiang, Y., et al. (2013). Oxymatrine Protects against Myocardial Injury via Inhibition of JAK2/STAT3 Signaling in Rat Septic Shock. Mol. Med. Rep. 7, 1293-1299. doi:10.3892/mmr.2013.1315

Zhao, P., Kuai, J., Gao, J., Sun, L., Wang, Y., and Yao, L. (2017). Delta Opioid Receptor Agonist Attenuates Lipopolysaccharide-Induced Myocardial Injury by Regulating Autophagy. Biochem. Biophysical Res. Commun. 492, 140-146. doi:10.1016/j.bbrc.2017.06.029

Zotti, T., Uva, A., Ferravante, A., Vessichelli, M., Scudiero, I., Ceccarelli, M., et al. (2011). TRAF7 Protein Promotes Lys-29-Linked Polyubiquitination of ІкB Kinase $(\mathrm{IKK} \gamma) / \mathrm{NF}-\mathrm{Kb}$ Essential Modulator (NEMO) and p65/RelA Protein and 
Represses NF-Kb Activation. J. Biol. Chem. 286 (26), 22924-22933. doi:10.1074/jbc.m110.215426

Conflict of Interest: The authors declare that the research was conducted in the absence of any commercial or financial relationships that could be construed as a potential conflict of interest.

Publisher's Note: All claims expressed in this article are solely those of the authors and do not necessarily represent those of their affiliated organizations, or those of the publisher, the editors and the reviewers. Any product that may be evaluated in this article, or claim that may be made by its manufacturer, is not guaranteed or endorsed by the publisher.

Copyright (c) 2021 Li, Zhang, Zhang and Hao. This is an open-access article distributed under the terms of the Creative Commons Attribution License (CC $B Y)$. The use, distribution or reproduction in other forums is permitted, provided the original author(s) and the copyright owner(s) are credited and that the original publication in this journal is cited, in accordance with accepted academic practice. No use, distribution or reproduction is permitted which does not comply with these terms. 